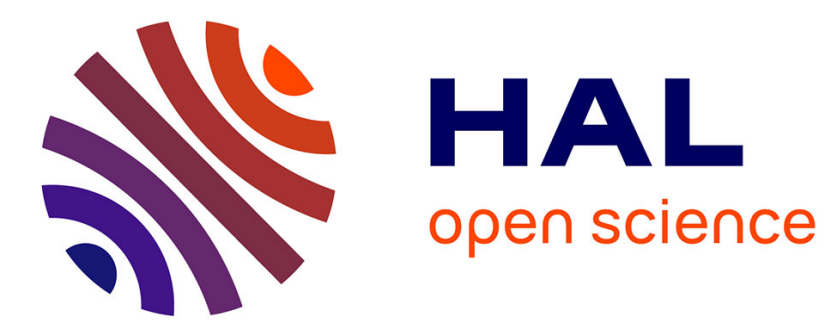

\title{
Structure, stability, and electronic properties of niobium-germanium and tantalum-germanium clusters
}

C. Siouani, S. Mahtout, Franck Rabilloud

\section{To cite this version:}

C. Siouani, S. Mahtout, Franck Rabilloud. Structure, stability, and electronic properties of niobiumgermanium and tantalum-germanium clusters. Journal of Molecular Modeling, 2019, 25 (5), pp.113. 10.1007/s00894-019-3988-5 . hal-02285869

\section{HAL Id: hal-02285869 \\ https://univ-lyon1.hal.science/hal-02285869}

Submitted on 12 Mar 2021

HAL is a multi-disciplinary open access archive for the deposit and dissemination of scientific research documents, whether they are published or not. The documents may come from teaching and research institutions in France or abroad, or from public or private research centers.
L'archive ouverte pluridisciplinaire HAL, est destinée au dépôt et à la diffusion de documents scientifiques de niveau recherche, publiés ou non, émanant des établissements d'enseignement et de recherche français ou étrangers, des laboratoires publics ou privés. 


\title{
Structure, Stability, and Electronic Properties of Niobium- Germanium and Tantalum-Germanium Clusters
}

\author{
C. SIOUANI ${ }^{a, b}$, S. MAHTOUT ${ }^{a}$ and F. RABILLOUD ${ }^{c}$ \\ ${ }^{a}$ Laboratoire de Physique Théorique, Faculté des Sciences Exactes, Université de Bejaia, \\ 06000 Bejaia, Algérie, \\ ${ }^{b}$ Département des Sciences de la matière, Faculté des Sciences, Université d'Alger 1, 16000 \\ Alger, Algérie. \\ ${ }^{c}$ Univ Lyon, Université Claude Bernard Lyon 1, CNRS, Institut Lumière Matière, F-69622, \\ Villeurbanne, France \\ Corresponding authors: mahtout_sofiane@yahoo.fr,franck.rabilloud@univ-lyon1.fr
}

\begin{abstract}
The structural, electronic and magnetic properties of niobium and tantalum doped germanium clusters $\mathrm{MGe}_{\mathrm{n}}(\mathrm{M}=\mathrm{Nb}$, Ta and $\mathrm{n}=1-19)$ are investigated by first principles calculations within the Density Functional Theory approach (DFT). The growth pattern behaviors, stabilities, and electronic properties are presented and discussed. Endohedral cagelike structures in which the metal atom is encapsulated are favored for $n \geq 10$. The doping metal atom contributes largely to strengthen the stability of the germanium cage-like structures with the binding energy ordered as follows $\mathrm{BE}\left(\mathrm{Ge}_{\mathrm{n}+1}\right)<\mathrm{BE}\left(\mathrm{VGe}_{\mathrm{n}}\right)<\mathrm{BE}\left(\mathrm{NbGe}_{\mathrm{n}}\right)<$ $\mathrm{BE}\left(\mathrm{TaGe}_{\mathrm{n}}\right)$. Our results highlight the relative high stability of $\mathrm{NbGe}_{15}, \mathrm{TaGe}_{15}$ and $\mathrm{VGe}_{14}$.
\end{abstract}

Keywords: clusters; Germanium clusters; metal-doped germanium clusters; DFT; ab initio calculations;

\section{Introduction}

Atomic clusters containing few atoms have attracted much attention during the last decades due to their physical and chemical properties which are generally much different compared to bulk systems. The properties of these small clusters are very sensitive to the geometrical structure and they change dramatically with the composition and the number of atoms. Nanoclusters promise to be used as building blocks in advanced materials with specific properties for many applications in nanosciences and nanotechnologies [1].

Germanium is an important element in the field of semiconductor materials. Small and medium-sized germanium clusters have been intensively studied in both theoretical and experimental fields [2-4]. While pure semiconductor clusters are chemically active due to unsaturated dangling bonds, the doping with a foreign atom may lead to a significant enhancement of the stability, for example by encapsulating one or more atoms inside the cluster in order to saturate the dangling bonds[5].

During the last decades, many theoretical and experimental researches on germanium clusters $\mathrm{Ge}_{\mathrm{n}}$ doped with different metal atoms have been reported [5-39]. Most of these works prove that the doping with a metal atom contributes to stabilize germanium cage structures and induce novel magnetic properties or special semiconductor behaviors. Among early 
works, the geometries, stabilities, and electronic and magnetic properties of $\mathrm{CuGe}_{\mathrm{n}}(\mathrm{n}=2$ 13) [6], $\mathrm{ThGe}_{\mathrm{n}}(\mathrm{n}=16,18,20)$ [5], $\mathrm{NiGe}_{\mathrm{n}}(\mathrm{n}=1-13)$ [7], $\mathrm{WGe}_{\mathrm{n}}(\mathrm{n}=1-17)$ [8], $\mathrm{CrGe}_{\mathrm{n}}(\mathrm{n}=1-$ 5) [9], $\mathrm{Ge}_{n} \mathrm{Si}_{\mathrm{m}}(\mathrm{m}+\mathrm{n}=5)$ [10], $\mathrm{CoGe}_{\mathrm{n}}(\mathrm{n}=1-13)$ [11], $\mathrm{Mo}_{2} \mathrm{Ge}_{\mathrm{n}}(\mathrm{n}=9-15)$ [12], $\mathrm{FeGe}_{\mathrm{n}}(\mathrm{n}=$ 9-16) [13], $\mathrm{Bi}_{2} \mathrm{Ge}_{\mathrm{n}-2}(\mathrm{n}=3-8,12)$ [14], $\mathrm{Fe}_{\mathrm{n}} \mathrm{Ge}_{\mathrm{m}}(\mathrm{n}+\mathrm{m} \leq 4)$ [15], $\mathrm{MnGe}_{\mathrm{n}}(\mathrm{n}=2-16)$ [16] clusters have been systematically investigated by using Density-Functional Theory (DFT) calculations. These studies concluded that the growth patterns depend on the nature of the doping metal atom. Particularly the charge-transfer mechanisms depend on the metal atom, and also on the size and the structure of the cluster. Most of the clusters prefer structures with a high-spin ground state and a large magnetic moment, for instance $\mathrm{CrGe}_{\mathrm{n}}$ [9]. The magnetic moment of the doped clusters mainly originates from the $3 d$ unpaired electrons of the substituted doping atom [11-13]. No quenching of the magnetic moment of the doping transition metal atom has been found for $\mathrm{Co}, \mathrm{Fe}$ and $\mathrm{Mn}$ doped small germanium clusters [11, 13, 16]. The magnetic coupling between iron and germanium atoms is generally antiferromagnetic-like and the charge transfer mainly occurs from $\mathrm{Fe}$ to $\mathrm{Ge}$ atoms in $\mathrm{Fe}_{\mathrm{n}} \mathrm{Ge}_{\mathrm{m}}$ clusters [15]. In the case of $\mathrm{Mo}_{2} \mathrm{Ge}_{n}$ clusters, the $\mathrm{Mo}_{2}$ dimer moves to the center of the cage and becomes completely encapsulated into the germanium clusters as the size increases [12].

In the last decade, many new investigations on metal atom doped germanium clusters have been reported. Physical properties of $\mathrm{TMGe}_{\mathrm{n}}(\mathrm{TM}=\mathrm{Sc}, \mathrm{Ti}, \mathrm{V} ; \mathrm{n}=14-20)$ [17], $\mathrm{NiGe}_{\mathrm{n}}(\mathrm{n}$ = 1-20) [18] and $\mathrm{CuGe}_{\mathrm{n}}(\mathrm{n}=1-20)$ clusters [19] have been investigated by bandyopadhyay and coworkers. They found that a relative high stability of TM (Sc, Ti, V) doped germanium clusters may be related to the formation of a filled shell free-electron gas inside the germanium cage or to the geometric effects [17]. The growth behavior, electronic and magnetic properties of $\mathrm{TMGe}_{\mathrm{n}}(\mathrm{TM}=\mathrm{Mn}, \mathrm{Co}, \mathrm{Ni}, \mathrm{Cr} ; \mathrm{n}=1-13)[20,21],(\mathrm{TM}=\mathrm{Ti}, \mathrm{Zr}$ and Hf; $n=1-20)$ [22], $\mathrm{Sn}_{m} \mathrm{Ge}_{\mathrm{n}}(\mathrm{m}+\mathrm{n} \leq 5)$ [23], $\mathrm{AlGe}_{\mathrm{n}}(\mathrm{n}=1-9)$ [24] clusters have been also investigated. It was found that the magnetic behavior of $\mathrm{TMGe}_{\mathrm{n}}(\mathrm{TM}=\mathrm{Mn}, \mathrm{Co}, \mathrm{Ni}, \mathrm{Cr})$ clusters is due to TM doping atoms and the magnetic moment is mainly localized at the TM site and neighbouring $\mathrm{Ge}$ atoms $[20,21]$. The $\mathrm{Al}$ atom does not enhance the binding energy of germanium clusters in $\mathrm{AlGe}_{n}$ [24]. The $\mathrm{CoGe}_{n}{ }^{-}(\mathrm{n}=2-11)$ [25] and $\mathrm{VGe}_{n}{ }^{-}(\mathrm{n}=3-12)$ [26] clusters were also investigated with anion photoelectron spectroscopy and density functional theory calculations. Both experiment and calculation show an electron transfer from the $\mathrm{Ge}_{\mathrm{n}}$ framework to the metal atom and a minimization of the magnetic moment that is related to the structural evolution from exo- to endohedrals.

Recently, a study of the multicharged ruthenium-doped germanium clusters $\mathrm{RuGe}_{n}{ }^{q}(n=2-12, q=-2,-3)$ has highlighted an inherent tendency of formation of endohedral cage [27] and the decreasing of the transfer of negative charge from the $\mathrm{Ge}_{\mathrm{n}}$ framework to the doping atom with the increasing ionization. A DFT investigation of the electronic and magnetic properties of medium-sized $\mathrm{CrGe}_{n}(15 \leq \mathrm{n} \leq 29)$ [28] has shown that the encapsulation of $\mathrm{Cr}$ atoms within $\mathrm{Ge}_{n}$ clusters leads to stable $\mathrm{CrGe}_{\mathrm{n}}$ cages. The atomic and electronic structure of both neutral and negatively charged $\mathrm{ZrGe}_{\mathrm{n}}(\mathrm{n}=1-21)$ and $\mathrm{AuGe}_{\mathrm{n}}(\mathrm{n}=$ 2-12) clusters have been studied using ab initio calculations and compared to the experimental photoelectron spectroscopy $[29,30]$. For $\mathrm{AuGe}_{\mathrm{n}}$, the metal atom prefers the peripheral position for clusters for $\mathrm{n}<11$ and the endohedral one for larger $n$.

Very recently, extensive studies [31, 32] of the equilibrium geometries and electronic and magnetic properties of vanadium and coinage metal doped germanium clusters, $\mathrm{MGe}_{\mathrm{n}}(\mathrm{M}$ $=\mathrm{V}, \mathrm{Cu}, \mathrm{Ag}, \mathrm{Au} ; \mathrm{n}=1-19$ ), have showed that the most stable clusters (which correspond to an endohedral cage-like structure for $\mathrm{VGe}_{14}$ and $\mathrm{CuGe}_{10}$, or a hollow cage for $\mathrm{AgGe}_{15}$ and 
$\mathrm{AuGe}_{15}$ ) present a peculiar electronic structure in which the valence electrons of the doping atom and $\mathrm{Ge}$ atoms are delocalized and exhibit a shell structure associated with the quasispherical geometry. Some properties of the very small clusters $\mathrm{VGe}_{\mathrm{n}}{ }^{-10}(\mathrm{n}=1-7)$ and $\mathrm{CoGe}_{\mathrm{n}}{ }^{-10}$ $(\mathrm{n}=1-3)$ have been investigated with the DFT and multi-configurational CASSCF/CASPT2 methods [33, 34, 35]; calculated vertical and adiabatic detachment energies were in agreement with the experimental results. A joint photoelectron spectroscopy and DFT study [36-37] of $\mathrm{Fe}_{2} \mathrm{Ge}_{\mathrm{n}}{ }^{-/ 0}$ ( $\left.\mathrm{n}=3-12\right)$ and $\mathrm{Cr}_{2} \mathrm{Ge}_{\mathrm{n}}{ }^{-}(\mathrm{n}=3-14)$ has suggested a high potential to change the magnetic behavior of germanium clusters by introducing transition-metal dopant atoms. The atomic structures of anionic clusters $\mathrm{ZrGe}_{\mathrm{n}}{ }^{-}(\mathrm{n}=8-20)$ have been explored by DFT calculations and compared to the available experimental electronic spectra [39]; the doped anion clusters present an exohedral structure for smaller sizes while the formation of endohedral cages is favored for $\mathrm{n} \geq 12$.

Our previous work on $\mathrm{VGe}_{\mathrm{n}}$ clusters [31] has enhanced the high stability of $\mathrm{VGe}_{14}$ with present an $O_{h}$ symmetry structure and a high binding energy, high HOMO-LUMO gap, high ionization potential, small electron affinity, and large chemical hardness. That cluster presents a peculiar electronic structure in which the valence electrons of $\mathrm{V}$ and Ge atoms are delocalized and exhibit a shell structure associated with the quasi-spherical geometry (1S $1 \mathrm{P}$ 1D $2 \mathrm{~S} 1 \mathrm{~F}$ etc.). That shell model, which was well-known in metal clusters and explained by the jellium model, was not expected in metal-doped germanium clusters. In the present work we focus on $\mathrm{NbGe}_{\mathrm{n}}$ and $\mathrm{TaGe}_{\mathrm{n}}(\mathrm{n}=1-19)$ clusters, since $\mathrm{Ta}, \mathrm{Nb}$, and $\mathrm{V}$ are in the same column of the periodic table, in order to see whether Ta and $\mathrm{Nb}$-doped $\mathrm{Ge}_{\mathrm{n}}$ clusters also present such peculiar electronic configurations. We aim to understand their structural, electronic and magnetic properties, and to characterize their evolution of the physicochemical properties as a function of the size, the shape and the composition. It is very important to determine the relation between the structural, electronic and magnetic properties since the magnetic properties depends on the electronic structure which in turn depends on the geometry. Therefore, a systematic study of these clusters is required to understand the physical and chemical properties. According to our knowledge, no investigation of the $\mathrm{NbGe}_{\mathrm{n}}$ and $\mathrm{TaGe}_{\mathrm{n}}$ clusters has been reported in the literature to date.

We think that this work would be useful to understand the different properties of these new systems and could provide powerful guidelines for other theoretical and experimental studies. In section 2 we give a brief description of the theoretical method and computational scheme used in this work. In Section 3, we present and compare the results and discussion of the obtained geometries, electronic and magnetic properties of the different $\mathrm{MGe}_{\mathrm{n}}$ clusters. Finally, Section 4 summarizes the main conclusions of our results.

\section{Computational methodology}

First-principles calculations using the generalized gradient approximation (GGA) with the Perdew-Burke-Ernzerhof (PBE) density functional [40] were performed by using the Siesta simulation package [41]. They have been performed by using the method of normconserving Troullier-Martins nonlocal pseudo-potentials [42, 43]. We used a double zeta (DZ) basis set for Ge atoms and double zeta basis plus polarization orbitals (DZP) for $\mathrm{Nb}$ and $\mathrm{Ta}$ atoms. A large cubic cell of $40 \AA$ edge length, with the periodic boundary conditions, was taken in order to avoid the interaction between the neighboring clusters. The $\mathrm{k}$ grid integration has been carried using the $\Gamma$ point approximation. The atomic positions have been optimized without any symmetry constraints and until the residual forces are smaller than $10^{-3} \mathrm{eV} / \AA$. 
A complete exploration of geometrical configurations is impossible. In the present work, a considerable number of possible initial structures (about 5-6 for very small clusters and about 50 for larger ones) were considered for each size. All isomeric structures obtained by substituting one $\mathrm{Ge}$ atom with a metal atom on different sites of the lowest-energy configuration of pure $\mathrm{Ge}_{\mathrm{n}+1}$ clusters [31] have been considered. We have also tested structures already published for $\mathrm{MGe}_{\mathrm{n}}(\mathrm{M}=\mathrm{V}, \mathrm{Ag}, \mathrm{Cu}, \mathrm{Au}, \mathrm{Ni}, \mathrm{Co}, \mathrm{Cr}$, etc. $)$ [18, 20, 21, 24, 31, 32], and try to build $\mathrm{MGe}_{\mathrm{n}}$ by adding one $\mathrm{Ge}$ atom to $\mathrm{MGe}_{\mathrm{n}-1}$. Several spin-multiplicity states were tested.

The stability of $\mathrm{Nb}$ and $\mathrm{Ta}$ doped germanium clusters can be studied by the calculation of the binding energy, the energy difference between the Highest Occupied Molecular Orbital (HOMO) and the Lowest Unoccupied Molecular Orbital (LUMO), and the second-order energy difference. The binding energies per atom of $\mathrm{MGe}_{\mathrm{n}}(\mathrm{M}=\mathrm{Nb}, \mathrm{Ta})$ are defined by the following formula:

$$
E_{b}\left(M G e_{n}\right)(\text { eV/atom })=\left(n E(\mathrm{Ge})+E(\mathrm{M})-E\left(\mathrm{MGe}_{\mathrm{n}}\right)\right) /(n+1)
$$

where $E(\mathrm{Ge})$ is the total energy of free Ge atom, $E(\mathrm{M})$ is the total energy of free $\mathrm{M}$ atom and $E\left(\mathrm{MGe}_{\mathrm{n}}\right)$ is the total energy of the $\mathrm{MGe}_{\mathrm{n}}$ cluster. The HOMO-LUMO gap is calculated from the energy of the orbitals:

$$
\Delta E(e V)=E(L U M O)-E(H O M O)
$$

The second-order energy difference for the ground-state $\mathrm{MGe}_{\mathrm{n}}(\mathrm{M}=\mathrm{Nb}$, Ta) clusters can be calculated by:

$$
\Delta_{2} E=E\left(M G e_{n+1}\right)+E\left(M G e_{n-1}\right)-2 E\left(M G e_{n}\right)
$$

where $E$ is the total energy of the most stable structure for each species.

At the present level of calculation, the bond lengths of $\mathrm{Ge}_{2}$ was found to be $2.450 \AA$, in good agreement with the estimated experimental data of $2.44 \AA$ [44]. The binding energy per atom, calculated to be $1.44 \mathrm{eV}$ which is also in good agreement with both theoretical $[6,9,21]$ and experimental $(\sim 1.35 \mathrm{eV})[45]$ data.

\section{Results and discussions}

\section{3-1. Structural properties}

Using the computation scheme described above, we have explored a number of isomers and determined the putative lowest-energy structure of all $\mathrm{MGe}_{\mathrm{n}}(\mathrm{M}=\mathrm{Nb}, \mathrm{Ta}$ and $\mathrm{n}=1-19$ ) clusters. The lowest-energy structure and some of their representative low-lying isomers are shown in Figures 1 and 2 for $\mathrm{NbGe}_{\mathrm{n}}$ and $\mathrm{TaGe}_{\mathrm{n}}$ respectively. The symmetry group, binding energy $\mathrm{E}_{\mathrm{b}}(\mathrm{eV} / \mathrm{atom}), \mathrm{HOMO}-\mathrm{LUMO}$ gap $\Delta \mathrm{E}(\mathrm{eV})$, the total spin magnetic moment, the vertical ionization potential VIP $(\mathrm{eV})$, the vertical electron affinity VEA $(\mathrm{eV})$, the chemical hardness $\eta(\mathrm{eV})$ and the average $\mathrm{Ge}-\mathrm{Ge}$ and $\mathrm{M}-\mathrm{Ge}$ bond lengths are summarized in Table 1 and Table 2 for all $\mathrm{NbGe}_{\mathrm{n}}$ and $\mathrm{TaGe}_{\mathrm{n}}$ clusters respectively. The most stable 
structures of $\mathrm{NbGe}_{\mathrm{n}}$ clusters are generally similar to those of $\mathrm{TaGe}_{\mathrm{n}}$ clusters. In the detailed description below, we compare the present results to those recently obtained for V-doped $\mathrm{Ge}_{\mathrm{n}}$ [31].

The electronic ground state of $\mathrm{NbGe}$ and TaGe dimers is a sextet with a bond length of 2.592 and $2.603 \AA$ respectively. The binding energy (per atom) calculated to be 1.230 and $1.358 \mathrm{eV}$ for $\mathrm{NbGe}$ and $\mathrm{TaGe}$ respectively, is smaller than that of $\mathrm{Ge}_{2}$ dimer (1.446 eV) [31]. The binding energy of TaGe is 0.160 and $0.128 \mathrm{eV}$ larger than that of $\mathrm{VGe}$ and $\mathrm{NbGe}$. For the trimers $\mathrm{NbGe}_{2}$ and $\mathrm{TaGe}_{2}$, the triangular structure with $C_{2 v}$ symmetry is found to be the lowest-energy structure. This ground-state structure was also obtained in the case of $\mathrm{Ge}_{3}$ and $\mathrm{VGe}_{2}$ trimers. $\mathrm{NbGe}_{3}$ is a quartet and its structure is a $C_{3 v}$ pyramid similar to that reported for $\mathrm{VGe}_{3}$, but the lowest-energy of $\mathrm{TaGe}_{3}$ is a doublet and presents only a $C_{s}$ symmetry since $\mathrm{Ge}_{3}$ triangle is no longer equilateral but becomes isosceles with two Ge-Ge bonds are enlarged from 2.72 to $2.90 \AA$. The planar structure with $C_{2 v}$ symmetry which is reported as the ground state structure for $\mathrm{Ge}_{4}$ is found to be less stable. The global minimum structure of the pentamers $\mathrm{NbGe}_{4}$ and $\mathrm{TaGe}_{4}$ is found to be a distorted rhombus with $C_{s}$ symmetry which is in agreement with the ground state structure of $\mathrm{VGe}_{4}$. The Ta-Ge average bond distance is respectively 0.070 and $0.081 \AA$ higher than $\mathrm{Nb}-\mathrm{Ge}$ and $\mathrm{V}-\mathrm{Ge}$ average bond lengths. For the hexamers $\mathrm{NbGe}_{5}$ and $\mathrm{TaGe}_{5}$, the square bipyramidal geometry with $C_{4 v}$ symmetry is found to be the lowest-energy structure. The obtained ground state structure is more regular than that obtained for $\mathrm{VGe}_{5}$ which has only a $C_{2 v}$ symmetry [31]. The Nb-Ge and Ta-Ge bond lengths are $2.631 \AA$ and $2.658 \AA$ respectively. The most stable isomer of the heptamers $\mathrm{NbGe}_{6}$ and $\mathrm{TaGe}_{6}$ is a bicapped pentagonal geometry with $C_{S}$ symmetry. The similar structure is found for the most stable isomers $\mathrm{Ge}_{7}$ and $\mathrm{VGe}_{6}$ with $D_{5 h}$ and $C_{2 v}$ point group symmetry respectively. For $\mathrm{NbGe}_{7}$ and $\mathrm{TaGe}_{7}$ clusters, the capped pentagonal bipyramid structure with $C_{s}$ symmetry is found to be the ground state structure, similar to the ground state of $\mathrm{Ge}_{8}$ and $\mathrm{VGe}_{7}$. The lowest-energy structure of the $\mathrm{NbGe}_{8}$ and $\mathrm{TaGe}_{8}$ clusters is a tricapped trigonal prism geometry with a $C_{2 v}$ symmetry. The same symmetry is obtained in the case of $\mathrm{VGe}_{8}$ with the binding energy of $2.966 \mathrm{eV} /$ atom [31]. In the case of $\mathrm{NbGe}_{9}$ and $\mathrm{TaGe}_{9}$ clusters, the lowest-energy structure can be viewed as a pentagonal bipyramid face-capped by three $\mathrm{Ge}$ atoms, it is much different from $\mathrm{VGe}_{9}$ which is formed by two distorted hexagonal prims and a $C_{s}$ symmetry. We can note that the binding energies of $\mathrm{NbGe}_{9}$ and $\mathrm{TaGe}_{9}$ are respectively 0.044 and $0.055 \mathrm{eV} /$ atom smaller comparatively to the ground state structure of $\mathrm{NbGe}_{8}$ and $\mathrm{TaGe}_{8}$ clusters which may be related to the loss of symmetry. For $\mathrm{NbGe}_{10}$ and $\mathrm{TaGe}_{10}$ clusters, the metal atom is partially encapsulated in an opened cage with $C_{2}$ symmetry. This structure has been already found as the most stable isomer for $\mathrm{VGe}_{10}$ cluster [31]. The average Ge-Ge and Ta-Ge bond lengths are $0.005 \AA$ and $0.109 \AA$ larger than Nb-Ge and V-Ge average bond lengths respectively. For the size $\mathrm{n}=11$, the optimized ground state structure of $\mathrm{Nb}$ doped $\mathrm{Ge}_{\mathrm{n}}$ clusters differ slightly from that of Ta-doped $\mathrm{Ge}_{\mathrm{n}}$. A distorted superposition of two rhombic structures with $C_{2}$ symmetry is found to be the lowest-energy isomer of $\mathrm{TaGe}_{11}$ which is consistent with the ground structure of $\mathrm{VGe}_{11}$. The $\mathrm{Nb}$ atom occupies a more central position and tends to form more bonds with germanium atoms, therefore $\mathrm{NbGe}_{11}$ seems to be more an opened cage with ten $\mathrm{Nb}-\mathrm{Ge}$ bonding. Its binding energy is $0.015 \mathrm{eV} /$ atom smaller than that of $\mathrm{NbGe}_{10}$.

Starting from $\mathrm{n}=12$, the endohedral structures where the $\mathrm{Nb}$ or Ta metal atom is highly coordinated and totally encapsulated inside a germanium cage appear, while the exohedral structures lie much higher than the endohedrals. Similar to $\mathrm{VGe}_{12}$ clusters, a perfect hexagonal prism isomer having a $D_{3 d}$ symmetry with the $\mathrm{Nb}$ or Ta doping atom encapsulated 
into a caged $\mathrm{Ge}_{12}$ framework is found to be the ground-state isomer in $\mathrm{NbGe}_{12}$ and $\mathrm{TaGe}_{12}$ clusters. These ground-state isomers have the shortest Ge-Ge bond lengths of 2.593 and $2.594 \AA$, respectively. However, a second isomer, labeled $\mathrm{NbGe}_{12}-\mathrm{b}$ and $\mathrm{TaGe}_{12}-\mathrm{b}$ respectively, with $C_{s}$ symmetry lies only 0.003 and $0.004 \mathrm{eV} /$ atom above the $D_{3 d}$-symmetry isomer at the present level of calculation. Then isomers are quasi-degenerate. The second structures is somewhat similar to the lowest-energy one but one Ge atom comes to cap a hexagonal face $\mathrm{Ge}_{6}$ and thus closing the cage on one side. In $\mathrm{NbGe}_{13}$ and $\mathrm{TaGe}_{13}$ clusters, the lowest-energy isomer is a hexagonal prism capped bowl kind of structure with $\mathrm{Nb}$ and $\mathrm{Ta}$ metal atoms inside the cage with $C_{3 v}$ symmetry. In the case of $\mathrm{VGe}_{13}$, the most stable structure is also a capped hexagonal prism but with the high $C_{6 v}$ symmetry. The average $\mathrm{Nb}-\mathrm{Ge}$ and $\mathrm{Ta}-$ Ge bond lengths are $0.192 \AA$ and $0.193 \AA$ larger than the average Ge-Ge bond length. The most stable isomer of $\mathrm{TaGe}_{13}$ is less stable than $\mathrm{TaGe}_{12}$ by only $0.002 \mathrm{eV} /$ atom. The lowestenergy structures of $\mathrm{NbGe}_{14}$ and $\mathrm{TaGe}_{14}$ are the perfect sealed cage structures with $C_{2}$ symmetry, the metal doping atom is highly coordinated and located at the center of the cage. The endohedral structures $\mathrm{NbGe}_{14}-\mathrm{b}$ and $\mathrm{TaGe}_{14}$-b with high $O_{h}$ symmetry, which have been reported as the ground state structure in $\mathrm{VGe}_{14}$ [31], are found at 0.069 and $0.017 \mathrm{eV} /$ atom respectively above the lowest-energy isomer. They do not compete for the ground state, but they are metastable since all frequencies are calculated to be positive.

The most stable structures for the sizes $\mathrm{n}=15,16$ and 17 obviously derive from the ground-state for $\mathrm{n}=14$ by adding one $\mathrm{Ge}$ atom, two $\mathrm{Ge}$ atoms and three $\mathrm{Ge}$ atoms, respectively. The lowest-energy structure of the $\mathrm{NbGe}_{15}$ and $\mathrm{TaGe}_{15}$ clusters has a $C_{2 v}$ symmetry with $\mathrm{Nb}-\mathrm{Ge}$ and Ta-Ge bond-lengths of 2.987 and $2.990 \AA$, respectively. This endohedral structure has already been found as the lowest-energy isomer in the case of $\mathrm{VGe}_{15}$. The ground state geometries obtained from $n=16$ to 18 for each species are all less stable than the corresponding $\mathrm{TaGe}_{15}$ and $\mathrm{NbGe}_{15}$ clusters. The lowest-energy structure of $\mathrm{NbGe}_{16}$ is $\mathrm{NbGe}_{16}$-a with $C_{1}$ point group symmetry and the lowest-energy isomer of $\mathrm{TaGe}_{16}$ is $\mathrm{TaGe}_{16}-\mathrm{a}$ with $C_{s}$ symmetry and the largest Ta-Ge average bond length of $3.019 \AA$. However, the $\mathrm{NbGe}_{16}$-b cluster with $C_{s}$ symmetry which has the largest $\mathrm{Nb}-\mathrm{Ge}$ average bond length of $3.016 \AA$ is found to lie only $0.002 \mathrm{eV} /$ atom above the lowest-energy isomer of $\mathrm{NbGe}_{16}$. The lowest-energy isomer of $\mathrm{VGe}_{16}$ is an irregular cage-like structure with $C_{1}$ symmetry. The endohedral ground state geometries for $\mathrm{n}=17$ belong the $C_{1}$ symmetry group with average $\mathrm{Nb}-\mathrm{Ge}$ and Ta-Ge bond distances of $2.948 \AA$ and $2.961 \AA$ respectively. A prolate structure has been previously predicted to be the ground state for $\mathrm{VGe}_{17}$ clusters. The lowest-energy structures of $\mathrm{NbGe}_{18}$ and $\mathrm{TaGe}_{18}$ are the irregular cage-like with respectively $C_{s}$ and $C_{1}$ symmetry and the doping atom completely encapsulated at the center of the cage. A prolatelike cage symmetry structure with $C_{1}$ was obtained as the lowest-energy isomer of $\mathrm{VGe}_{18}$ clusters. For $\mathrm{NbGe}_{19}$, two structures ( $\mathrm{NbGe}_{19}$-a and $\left.\mathrm{NbGe}_{19}-\mathrm{b}\right)$ compete for the lowest-energy isomer. In the lowest-energy isomer $\left(\mathrm{NbGe}_{19}-\mathrm{a}\right)$, the $\mathrm{Ge}-\mathrm{Ge}$ average bond length is much larger ( 2.806 vs $2.730 \AA)$ and the Nb-Ge average bond length is much shorter (2.950 vs 2.978 $\AA$ ). The lowest-energy isomer for $\mathrm{TaGe}_{19}$ cluster has the shortest $\mathrm{Ge}-\mathrm{Ge}$ and the largest Ta-Ge average bond lengths of 2.696 and $3.009 \AA$ respectively. The binding energies of $\mathrm{NbGe}_{19}$ and $\mathrm{TaGe}_{19}$ are respectively 0.010 and $0.029 \mathrm{eV} /$ atom larger comparatively to the ground state structures of $\mathrm{NbGe}_{18}$ and $\mathrm{TaGe}_{18}$ clusters.

\section{3-2. Electronic properties}

\section{Binding energy}


By using the formula (1), we calculate the binding energies for all the $\mathrm{MGe}_{\mathrm{n}}(\mathrm{M}=\mathrm{Nb}$, Ta and $n=1-19$ ) clusters. The obtained results are listed in Table 1 and 2 and their evolution with the cluster size are plotted in Figure 3. The size dependence shows an increasing of the binding energies for all pure and $\mathrm{M}$-doped $(\mathrm{M}=\mathrm{V}, \mathrm{Nb}, \mathrm{Ta})$ germanium clusters: a dramatic increasing of the binding energy is observed for the very small size $(n<8)$, then the binding energy increases more smoothly. We also observe that the binding energy of $\mathrm{TaGe}_{n}$ clusters are generally the largest comparatively to the other species followed by the binding energies of $\mathrm{NbGe}_{\mathrm{n}}$, then the binding energy of $\mathrm{VGe}_{\mathrm{n}}$ and finally the binding energy of pure corresponding germanium clusters $\mathrm{Ge}_{\mathrm{n}+1}$. Doping with $\mathrm{Nb}$ (resp. V) enhances the stability of $\mathrm{Ge}_{\mathrm{n}}$ clusters for $\mathrm{n} \geq 7$ (resp. 8), while doping with Ta has always a stabilizing character. The nature of bonding between the $\mathrm{M}$ atom and neighboring $\mathrm{Ge}$ atoms can explained this difference in the evolution of binding energy as a function of the doping atom species. Ta presents a stronger covalent character than $\mathrm{Nb}$ which in turn is more covalent than the vanadium. Thus the binding energy of the dimer TaGe, NbGe, VGe is calculated at 1.358, $1.230,1.198 \mathrm{eV} /$ atom respectively.

Additionally, the average binding energy curve presents a local maximum value at $\mathrm{n}=$ 8 and 15 for both $\mathrm{Nb}$ - and $\mathrm{Ta}$-doped $\mathrm{Ge}_{\mathrm{n}}$ implying that the clusters are relatively more stable than their neighbors. Actually, the local maximum for $n=8$ is due to the relative low stability of metal doped $\mathrm{Ge}_{9}$, likely related to the loss of symmetry and a relatively low coordination of the metal atom. Then, the largest value of binding energy is observed in the case of $\mathrm{TaGe}_{15}$ and $\mathrm{NbGe}_{15}$.

Another parameter which can reflect the stability of the small clusters is the secondorder energy difference $\left(\Delta_{2} E\right)$ defined by the relation (3). It is physically related to the experimental relative abundance of the corresponding element in the mass spectroscopy experiments. The calculated second-order energy difference of the lowest-energy isomers of different species studied in this work are shown in Figure 4. As we can see, the pronounced positive values of $\Delta_{2} \mathrm{E}$ are observed for $\mathrm{Nb}-\mathrm{TaGe}_{8}$ and $\mathrm{V}-\mathrm{Nb}-\mathrm{TaGe}_{10,12,15}$ indicating that these clusters may have special stabilities.

$\mathrm{Nb}$ - and Ta-doped $\mathrm{Ge}_{15}$ present a relative high stability, while the most stable structure for V-doped $\mathrm{Ge}_{\mathrm{n}}$ was obtained for the size $\mathrm{n}=14$ for which a perfect $O_{h}$-symmetry cage was obtained [31]. The atomic radius of $\mathrm{Nb}$ and $\mathrm{Ta}$ being slightly higher than that of $\mathrm{V}$, it was probable that the optimal cage would be obtained for $\mathrm{n}$ slightly greater than 14 . The high stability of $\mathrm{VGe}_{14}$ was associated to a peculiar electronic structure since the valence electrons of both $\mathrm{Ge}$ and $\mathrm{V}$ were found to be delocalized and exhibit a shell structure associated to the quasi-spherical geometry, with the following occupation: $1 \mathrm{~S}^{2} 1 \mathrm{P}^{6} 1 \mathrm{D}^{10} 2 \mathrm{~S}^{2} 1 \mathrm{~F}^{14} 3 \mathrm{~S}^{2} 2 \mathrm{P}^{6} 1 \mathrm{G}^{15}$ $2 \mathrm{D}^{4}$ [31]. In Figure 5, we show the density of states (DOS) and the Kohn-Sham orbitals calculated at PBE/cc-pvtz level with the software Gaussian09 [46] in the case of TaGe ${ }_{15}$. The $3 s$ and $3 p$ valence electrons of Ge and the five $s$ and $d$ valence electrons of Ta exhibit a shell structure associated to the somewhat spherical structure. We can easily distinguish the character of the orbitals, though there are some little deviations from a perfect sphere due to explicit location of atoms and the $C_{2 v}$ symmetry instead of $K_{h}$ (the symmetry of the atom). The 65 valence electrons of the cluster are organized with the following occupations: $1 \mathrm{~S}^{2} 1 \mathrm{P}^{6}$ $1 \mathrm{D}^{10} 1 \mathrm{~F}^{14} 2 \mathrm{~S}^{2} 2 \mathrm{P}^{6} 1 \mathrm{G}^{18} 2 \mathrm{D}^{6} 1 \mathrm{H}^{1}$. The number of electrons does not exactly fit with shell 
closings numbers, but the pooling of electrons and the organization in shell contributes to the high stability of the cluster. Similar results are found for $\mathrm{NbGe}_{15}$.

\section{HOMO-LUMO gaps}

The HOMO-LUMO gap is one important parameter that characterizes the chemical stability of the small clusters. A small value of HOMO-LUMO energy gap corresponds to a high chemical reactivity while a large value is related to an enhanced chemical stability. The size dependence of the calculated HOMO-LUMO gaps for all the ground-state structures is shown in Figure 6. An oscillating behavior is observed in the evolution of HOMO-LUMO gaps as the size increases. The HOMO-LUMO gaps of metal doped germanium clusters are generally smaller than that of the corresponding pure germanium cluster which means the doping metal atom enhances the reactivity of relevant clusters and favors the apparition of the metallic behavior, especially for smallest clusters where the metal is located at an exohedral position. For the cage-like structures, $\mathrm{VGe}_{12-14}$ present clearly a higher gap than $\mathrm{Nb}$ - and $\mathrm{Ta}-$ doped clusters, indicating that these clusters may have a relative low reactivity.

\section{VIP, VEA and $\eta$}

The vertical ionization potential (VIP) and the vertical electron affinity (VEA) are two important parameters which can determine the chemical stability behavior of the small clusters. The VIP is defined by the energy difference between the cationic $E\left(M G e_{n}\right)^{+}$and neutral clusters calculated at the equilibrium geometry of the neutral $\mathrm{MGe}_{\mathrm{n}}$ cluster, the VEA is the energy difference between the neutral $E\left(M G e_{n}\right)$ and the anionic clusters calculated at the geometry of the neutral cluster, as given in the following equations:

$$
\begin{gathered}
V I P=E\left(M G e_{n}\right)^{+}-E\left(M G e_{n}\right) \\
V E A=E\left(M G e_{n}\right)-E\left(M G e_{n}\right)^{-}
\end{gathered}
$$

Results are reported in Tables 1 and 2 for $\mathrm{NbGe}_{\mathrm{n}}$ and $\mathrm{TaGe}_{\mathrm{n}}$ clusters and their evolution as a function of the cluster size are plotted in Figures 7 and 8 respectively. VIP values are between 6 and $7.3 \mathrm{eV}$. An oscillating behavior is observed in the evolution of VIP for $\mathrm{Nb}$ and $\mathrm{Ta}$ doped germanium clusters. Local maxima are found for $n=10,12$, and 14 . The effect of the doping is clearly visible for very small $n$ and for $n>15$ where the metal atom induces a significant decrease of the VIP, but for $n=10-15$ the effect of the dopant is weak because the metal is highly coordinated in a compact cage.

In Figure 8 we see that the VEA is sensitive to the size and shows an increasing evolution with the increasing cluster size which indicates that the clusters with large size will capture an electron more easily. The metal doped $\mathrm{Ge}_{n}$ have a stronger VEA than the corresponding $\mathrm{Ge}_{\mathrm{n}+1}$ cluster, except for $\mathrm{n}=14$.

The chemical hardness $(\eta)$ is defined as the difference between the vertical ionization potential and electronic affinity as:

$$
\eta=\mathrm{VIP}-\mathrm{VEA}
$$


It is considered as a good parameter to understand the chemical stability of small clusters. The clusters with high values of hardness are less reactive [47]. The size dependence of the chemical hardness for all $\mathrm{MGe}_{\mathrm{n}}$ clusters are shown in Figure 9. The value of $\eta$ presents a roughly decreasing evolution with increasing size for both $\mathrm{NbGe}_{\mathrm{n}}$ and $\mathrm{TaGe}_{\mathrm{n}}$ without peculiar values, except a local minima for $\mathrm{n}=11$, already visible for $\mathrm{Ge}_{\mathrm{n}+1}$. In contrast the size dependence of $\eta$ for $V$-doped $\mathrm{Ge}_{\mathrm{n}}$ clusters highlights the size $\mathrm{n}=14$ which presents the highest stability.

\section{3-3. Magnetic properties}

The magnetic properties of the small $\mathrm{Nb}-\mathrm{Ta}-\mathrm{Ge}_{\mathrm{n}}$ clusters is discussed on the basis of the total spin magnetic moment (TSMM) as the difference between the total Mulliken charge populations in spin up and spin down electrons. The calculated TSMM for all isomers are reported in Tables 1 and 2. As we can see, the TSMM is generally equal to $1 \mu_{\mathrm{B}}$ except for the very small clusters where $\mu=5 \mu_{\mathrm{B}}$ for $\mathrm{NbGe}$ and $3 \mu_{\mathrm{B}}$ for $\mathrm{NbGe}_{2,3}$. For $\mathrm{TaGe}_{\mathrm{n}}$ clusters the TSMM is 5 and $3 \mu_{\mathrm{B}}$ for TaGe and $\mathrm{TaGe}_{2}$ respectively. Partial densities of states in Figure 10 in order to examine the contribution of different valence orbitals ( $s, p$ and d) of the components. The spin up densities is plotted as positive and the spin down as negative. For $\mathrm{NbGe}_{1}$ which have the high value of $5 \mu \mathrm{B}$, the TSMM is due to the contribution of two species by $4 \mathrm{~s}$ and $4 \mathrm{p}$ orbitals of $\mathrm{Ge}$ and the $4 \mathrm{~d}$ orbital of $\mathrm{Nb}$ atom. However, in the $\mathrm{NbGe}_{2}$ and $\mathrm{NbGe}_{3}$ clusters, the TSMM is mainly due to the $4 \mathrm{~d}$ orbitals of Niobium atom. In the case of $\mathrm{TaGe}_{\mathrm{n}}$ clusters all of the valence orbitals participate to the TSMM with a large contribution of the $5 \mathrm{~d}$ orbital of the Tantalum atom. In all of other clusters the TSMM of the doping atom is quenched, it should be due to orbital hybridizations and charge transfers between $M$ and surrounding $\mathrm{Ge}$ atoms.

\section{Conclusion}

First-principles DFT calculations have been performed to study the structures, stabilities, electronic and magnetic properties of $\mathrm{Nb}$ and $\mathrm{Ta}$ atoms doped germanium clusters, $\mathrm{MGe}_{\mathrm{n}}(\mathrm{M}=\mathrm{Nb}$, Ta and $\mathrm{n}=1-19)$. The growth pattern for $\mathrm{MGe}_{\mathrm{n}}(\mathrm{M}=\mathrm{Nb}$, Ta) shows that the $\mathrm{M}$ atom occupies a peripheral position for very small clusters $(n<10)$, while for $n \geq 10$ the endohedral structures in which the germanium cage encapsulates the metal atom are strongly favored. The binding energy increases with the increasing cluster size for all $\mathrm{MGe}_{n}(\mathrm{M}=\mathrm{Nb}$, $\mathrm{Ta}$ ) clusters and the $\mathrm{M}$ atoms enhances the stabilities of doped clusters comparatively to that of the corresponding pure germanium cluster. This stability is related to the pooling of valence electrons from both germanium and metal atoms. $\mathrm{TaGe}_{n}$ clusters present the highest stabilities. $\mathrm{TaGe}_{15}$ and $\mathrm{NbGe}_{15}$ are predicted to present a relative high stability. All of the isomers of $\mathrm{Nb}$ and $\mathrm{Ta}$ doped germanium clusters have the total spin magnetic moment equal to $1 \mu_{\text {в }}$ except for the very small size ( $\mathrm{n} \leq 3$ for $\mathrm{NbGe}_{\mathrm{n}}$ and $\mathrm{n} \leq 2$ for $\mathrm{TaGe}_{\mathrm{n}}$ ). PDOS analysis reveals the high total spin magnetic moment for the very small clusters is due to the contribution of the different valence orbitals with a large domination of $4 \mathrm{~d}$ orbitals of $\mathrm{Nb}$ and $5 \mathrm{~d}$ orbitals of Ta atoms. Finally, we hope that these results might be helpful for further theoretical and experimental investigations on future nano-sized materials.

\section{Acknowledgement}

FR thanks the GENCI-IDRIS (Grant A0050807662) center for generous allocation of computational time. 


\section{References}

[1] Handbook of Nanophysics clusters and Fullerenes, edited by Klaus D. Sattler, CRC Press, 2017. ISBN 9781138115101.

[2] A. A. Shvartsburg, B. Liu, Z.-Y. Lu, C.-Z. Wang, M. F. Jarrold, K.-M. Ho, Structures of Germanium Clusters: Where the Growth Patterns of Silicon and Germanium Clusters Diverge, Phys. Rev. Lett. 83 (1999) 2167.

[3] S. Yoshida, K. Fuke, Photoionization studies of germanium and tin clusters in the energy region of 5.0-8.8 eV: Ionization potentials for $\mathrm{Ge}_{\mathrm{n}}(\mathrm{n}=2-57)$ and $\mathrm{Sn}_{\mathrm{n}}(\mathrm{n}=2-41)$, J. Chem. Phys. 111 (1999) 3880.

[4] S. Bals, S. Van Aert, C.P. Romero, K. Lauwaet, M.J. Van Bael, B. Schoeters, B. Partoens, E. Yücelen, P. Lievens P.; G. Van Tendeloo, Atomic scale dynamics of ultrasmall germanium clusters, Nat. Comm. 3 (2012) 897.

[5] A. K. Singh, V. Kumar, Y. Kawazoe, Thorium Encapsulated Caged Clusters of Germanium: Th@ $\mathrm{Ge}_{\mathrm{n}}, \mathrm{n}=16,18$, and 20, J. Phys. Chem. B 109 (2005) 15187-15189.

[6] J. Wang, J. G. Han, A Computational Investigation of Copper-Doped Germanium and Germanium Clusters by the Density-Functional Theory, J. Chem. Phys. 123 (2005) 244303.

[7] J. Wang, J. G. Han, A Theoretical Study on Growth Patterns of Ni-Doped Germanium Clusters, J. Phys. Chem. B 110 (2006) 7820-7827.

[8] J. Wang, J. G. Han, Geometries and Electronic Properties of the Tungsten-Doped Germanium Clusters: $W_{G}(n=1-17)$, J. Phys. Chem. A 110 (2006) 12670-12677.

[9] X. J. Hou, G. Gopakumar, P. Lievens, M. T. Nguyen, Chromium-Doped Germanium Clusters $\mathrm{CrGe}_{\mathrm{n}}(\mathrm{n}=1-5)$ : Geometry, Electronic Structure, and Topology of Chemical Bonding, J. Phys. Chem. A 111 (2007) 13544-13553.

[10] P. Wielgus, S. Roszak, D. Majumdar, J. Saloni, J. Leszczynski, Theoretical Studies on the Bonding and Thermodynamic Properties of $\mathrm{Ge}_{n} \mathrm{Si}_{\mathrm{m}}(\mathrm{m}+\mathrm{n}=5)$ Clusters: The Precursors of Germanium/Silicon Nanomaterials, J. Chem. Phys. 128 (2008) 144305.

[11] D. Jing, F. Tian, Y. Wang, No Quenching of Magnetic Moment for the $\mathrm{Ge}_{\mathrm{n}} \mathrm{Co}(\mathrm{n}=1-13)$ Clusters: First Principles Calculations, J. Chem. Phys. 128 (2008) 124319.

[12] J. Wang, J. G. Han, Geometries, Stabilities, and Vibrational Properties of Bimetallic Mo2-Doped $\mathrm{Ge}_{\mathrm{n}}(\mathrm{n}=9-15)$ Clusters: A Density Functional Investigation, J. Phys. Chem. A 112 (2008) 3224-3230.

[13] W. J. Zhao, Y. X. Wang, Geometries, Stabilities, and Electronic Properties of FeGe $\mathrm{n}_{\mathrm{n}}(\mathrm{n}=$ 9-16) Clusters: Density-Functional Theory Investigations, Chem. Phys. 352 (2008) 291-296.

[14] A. D. Zdetsis, Silicon-Bismuth and Germanium-Bismuth Clusters of High Stability, J. Phys. Chem. A 113 (2009) 12079-12087.

[15] E. M. Sosa-Hernandez, P. G. Alvarado-Leyva, Magnetic Properties of Stable Structures of Small Binary $\mathrm{Fe}_{n} \mathrm{Ge}_{\mathrm{m}}(\mathrm{n}+\mathrm{m} \leq 4)$ Clusters, Phys. E 42 (2009) 17-21. 
[16] W. J. Zhao, Y. X. Wang, Geometries, Stabilities, and Magnetic Properties of $\operatorname{MnGe}_{\mathrm{n}}(\mathrm{n}=$ 2-16) Clusters: Density-Functional Theory Investigations, J. Mol. Struct.: THEOCHEM 901 (2009) 18-23.

[17] D. Bandyopadhyay, P. Kaur, P. Sen, New Insights into Applicability of ElectronCounting Rules in Transition Metal Encapsulating Ge Cage Clusters, J. Phys. Chem. A 114 (2010) 12986-12991.

[18] D. Bandyopadhyay, P. Sen, Density Functional Investigation of Structure and Stability of $\mathrm{Ge}_{\mathrm{n}}$ and $\mathrm{Ge}_{\mathrm{n}} \mathrm{Ni}(\mathrm{n}=1-20)$ Clusters: Validity of the Electron Counting Rule, J. Phys. Chem. A 114 (2010) 1835-1842.

[19] D. Bandyopadhyay, Architectures, Electronic Structures, and Stabilities of Cu-doped $\mathrm{Ge}_{\mathrm{n}}$ Clusters: Density Functional Modeling, J. Mol. Model. 18 (2012) 3887-3902.

[20] N. Kapila, V. K. Jindal, H. Sharma, Structural, Electronic and Magnetic Properties of $\mathrm{Mn}, \mathrm{Co}, \mathrm{Ni}$ in $\mathrm{Ge}_{\mathrm{n}}$ for $(\mathrm{n}=1-13)$, Phys. B 406 (2011) 4612-4619.

[21] N. Kapila, I. Garg, V. K. Jindal, H. Sharma, First Principle Investigation into Structural Growth and Magnetic Properties in $\mathrm{Ge}_{\mathrm{n}} \mathrm{Cr}$ Clusters for $\mathrm{n}=1-13$, J. Magn. Magn. Mater. 324 (2012) 2885-2893.

[22] M. Kumar, N. Bhattacharyya, D. Bandyopadhyay, Architecture, Electronic Structure and Stability of TM@Ge $(\mathrm{TM}=\mathrm{Ti}, \mathrm{Zr}$ and Hf; $\mathrm{n}=1-20)$ Clusters: a Density Functional Modeling, J. Mol. Model. 18 (2012) 405-418.

[23] P. N. Samanta, K. K. Das, Electronic Structure, Bonding, and Properties of $\mathrm{Sn}_{\mathrm{m}} \mathrm{Ge}_{\mathrm{n}}(\mathrm{m}+$ $\mathrm{n} \leq 5$ ) Clusters: A DFT Study, Comput. Theor. Chem. 980 (2012) 123-132.

[24] S. Shi, Y. Liu, C. Zhang, B. Deng, G. Jiang, A Computational Investigation of Aluminum-Doped Germanium Clusters by Density Functional Theory Study, Comput. Theor. Chem. 1054 (2015) 8-15.

[25] X. J. Deng, X. Y. Kong, X. L. Xu, H. G. Xu, W. J. Zheng, Structural and Magnetic Properties of $\mathrm{CoGe}_{\mathrm{n}}{ }^{-}(\mathrm{n}=2-11)$ Clusters: Photoelectron Spectroscopy and Density Functional Calculations, Chem. Phys. Chem. 15 (2014) 3987-3993.

[26] X.-J. Deng, X.-Y. Kong, H.-G. Xu, X.-L. Xu, G. Feng, W.-J. Zheng, Photoelectron Spectroscopy and Density Functional Calculations of $\mathrm{VGe}_{n}{ }^{-}(\mathrm{n}=3-12)$ Clusters, J. Phys. Chem. C 119 (2015) 11048-11055.

[27] Y. Jin, Y. Tian, X. Kuang, C. Lu, J. L. Cabellos, S. Mondal, G. Merino, Structural and Electronic Properties of Ruthenium-Doped Germanium Clusters, J. Phys. Chem. C 120 (2016) 8399-8404.

[28] S. Mahtout, Y. Tariket, Electronic and Magnetic Properties of $\mathrm{CrGe}_{n}(15 \leq \mathrm{n} \leq 29)$ Clusters: A DFT Study, Chem. Phys. 472 (2016) 270-277.

[29] S. Jaiswal, V. Kumar, Growth behavior and electronic structure of neutral and anion $\mathrm{ZrGe}_{\mathrm{n}}(\mathrm{n}=1-21)$ clusters, Comput. Theor. Chem. 1075 (2016) 87-97. 
[30] S.-J. Lu, L.-R. Hu, X.-L. Xu, H.-G. Xu, H. Chen, W.-J. Zheng, Transition from exohedral to endohedral structures of $\mathrm{AuGe}_{n}(\mathrm{n}=2-12)$ clusters: photoelectron spectroscopy and ab initio calculations, Phys. Chem. Chem. Phys. 18 (2016) 20321.

[31] C. Siouani, S. Mahtout, S. Safer, F. Rabilloud, Structure, Stability, and electronic and magnetic properties of $\mathrm{VGe}_{\mathrm{n}}(\mathrm{n}=1$ 1-19) clusters, J. Phys. Chem. A 121 (2017) 3540-3554.

[32] S. Mahtout, C. Siouani, S. Safer, F. Rabilloud, Growth Behavior and Electronic Structure of Noble Metal-Doped Germanium Clusters, J. Phys. Chem. A 122 (2018) 662-677.

[33] V. T. Tran, M. T. Nguyen, Q. T. Tran, A Computational Investigation of the Geometrical and Electronic Structures of $\mathrm{VGe}_{\mathrm{n}}{ }^{-10}(\mathrm{n}=1-4)$ Clusters by Density Functional Theory and Multiconfigurational CASSCF/CASPT2 Method, J. Phys. Chem. A 121 (2017) 7787-7796.

[34] V. T. Tran, Q. T. Tran, The Electronic Structures of $\mathrm{CoGe}_{\mathrm{n}}{ }^{-10}(\mathrm{n}=1-3)$ Clusters from Multiconfigurational CASSCF/CASPT2 and RASSCF/RASPT2 Calculations, J. Phys. Chem. A 122 (2018) 6407-6415.

[35] V. T. Tran, Q. T. Tran, Spin State Energetics of $\mathrm{VGe}_{\mathrm{n}}{ }^{-10}(\mathrm{n}=5-7)$ Clusters and New Assignments of the Anion Photoelectron Spectra, J. Comput. Chem. 39 (2018), 2103-2109.

[36] X. Q. Liang, X. J. Deng, S. J. Lu, X. Huang, J. Zhao, H. G. Xu, W.-J. Zheng, X. C. Zeng, Probing Structural, Electronic and Magnetic Properties of Iron-doped Semiconductor Clusters $\mathrm{Fe}_{2} \mathrm{Ge}_{\mathrm{n}}{ }^{-10}(\mathrm{n}=3-12)$ via Joint Photoelectron Spectroscopy and Density-Functional Study, J. Phys. Chem. C 121 (2017) 7037-7046.

[37] X. Q. Liang, X. Kong, S. J. Lu, Y. Huang, J. Zhao, H. G. Xu, W. Zheng, X. C. Zeng, Structural Evolution and Magnetic Properties of Anionic Clusters $\mathrm{Cr}_{2} \mathrm{Ge}_{\mathrm{n}}$ (n = 3-14): Photoelectron Spectroscopy and Density Functional Theory Computation, J. Phys. Condens. Matter, 30 (2018) 335501.

[38] S. E. Fioressi, D. E. Bacelo, Structures and energetics of $\mathrm{Be}_{n} \mathrm{Ge}_{n}(\mathrm{n}=1-5)$ and $\mathrm{Be}_{2 \mathrm{n}} \mathrm{Ge}_{\mathrm{n}}$ $(\mathrm{n}=1-4)$ clusters, Mol. Phys. 117 (2017) 1502-1513.

[39] N. A. Borshch, S. I. Kurganskii, Atomic Structure and Electronic Properties of Anionic Germanium-Zirconium Clusters, Inorg. Mat. 54 (2018) 1-7.

[40] J. P. Perdew, K. Burke, M. Ernzerhof, Generalized Gradient Approximation Made simple, Phys. Rev. Lett. 77 (1996) 3865-3868.

[41] J. M. Soler, E. Artacho, J. D. Gale, A. García, J. Junquera, P. Ordejón, D. SánchezPortal, The SIESTA Method for Ab Initio Order-N Materials Simulation, J. Phys.: Condens. Matter 14 (2002) 2745-2779.

[42] N. Troullier, J. L. Martins, Efficient Pseudopotentials for Plane-Wave Calculations, Phys. Rev. B: Condens. Matter Mater. Phys. 43 (1991) 1993-2006.

[43] L. Kleinman, D. M. Bylander, Efficacious Form for Model Pseudopotentials, Phys. Rev. Lett. 48 (1982) 1425-1428. 
[44] G. V. Gadiyak, Y. N. Morokov, A. G. Mukhachev, S. V. Chernov, Electron Density Functional Method for Molecular System Calculations, J. Struct. Chem. 22 (1982) 670-674.

[45] J. E. Kingcade, H. M. Nagarathna-Naik, I. Shim, K. A. Gingerich, Electronic structure and bonding of the molecule $\mathrm{Ge}_{2}$ from all-electron ab initio calculations and equilibrium measurements, J. Phys. Chem. 90 (1986) 2830-2834.

[46] M. J. Frisch et al., Gaussian09, Revision D.01, Gaussian Inc., Wallingford CT, 2013.

[47] R. G. Parr, W. Yang, Density Functional Theory of Atoms and Molecules; Oxford University Press: New York, 1989. 
Table 1. Symmetry group, binding energy $E_{b}$ (eV/atom), HOMO-LUMO gap $\Delta E(e V)$, vertical ionization potential VIP $(\mathrm{eV})$, vertical electron affinity VEA $(\mathrm{eV})$, chemical hardness $\eta(\mathrm{eV})$ and average bond length aGe-Ge and $\mathrm{a}_{\mathrm{Ge}-\mathrm{Nb}}(\AA)$ for $\mathrm{NbGe}_{\mathrm{n}}$ clusters. Data for the lowestenergy isomer are in bold.

\begin{tabular}{|c|c|c|c|c|c|c|c|c|c|}
\hline $\mathrm{n}$ & $\begin{array}{c}\text { Label- } \\
\text { symmetry }\end{array}$ & $\begin{array}{c}E_{b} \\
\text { (eV/atom) }\end{array}$ & $\begin{array}{c}\Delta E \\
(\mathrm{eV})\end{array}$ & $\begin{array}{c}\boldsymbol{\mu} \\
\left(\mu_{\mathrm{B}}\right)\end{array}$ & $\begin{array}{l}\text { VIP } \\
(\mathrm{eV})\end{array}$ & $\begin{array}{l}\text { VEA } \\
(\mathrm{eV})\end{array}$ & $\begin{array}{c}\boldsymbol{\eta} \\
(\mathrm{eV})\end{array}$ & $\begin{array}{c}\text { aGe-Ge } \\
(\AA)\end{array}$ & $\begin{array}{c}\text { aGe-Nb } \\
(\AA)\end{array}$ \\
\hline 1 & a- $\mathbf{C}_{\infty \mathrm{v}}$ & 1.230 & 0.704 & 5 & 6.645 & 0.697 & 5.948 & - & 2.592 \\
\hline \multirow[t]{2}{*}{2} & $a-C_{2 v}$ & 2.198 & 1.060 & 3 & 7.083 & 0.881 & 6.202 & 2.432 & 2.596 \\
\hline & b- $D_{\infty \mathrm{h}}$ & 1.375 & 1.177 & 9 & 6.712 & 1.925 & 4.787 & - & 2.728 \\
\hline \multirow[t]{3}{*}{3} & a- $C_{3 v}$ & 2.370 & 0.406 & 3 & 6.242 & 1.551 & 4.691 & 2.682 & 2.695 \\
\hline & b- $C_{2 v}$ & 2.357 & 0.468 & 3 & 6.551 & 1.599 & 4.952 & 2.425 & 2.731 \\
\hline & $\mathrm{c}-\mathrm{C}_{\mathrm{s}}$ & 2.024 & 0.261 & 5 & 6.902 & 2.057 & 4.845 & 2.466 & 2.627 \\
\hline \multirow[t]{5}{*}{4} & a- $C_{s}$ & 2.613 & 0.424 & 1 & 6.786 & 1.930 & 4.856 & 2.813 & 2.611 \\
\hline & b- $C_{2}$ & 2.573 & 0.295 & 3 & 6.556 & 1.776 & 4.780 & 2.660 & 2.794 \\
\hline & c- $\mathrm{C}_{2}$ & 2.500 & 0.507 & 3 & 6.386 & 1.600 & 4.786 & 2.548 & 2.598 \\
\hline & $\mathrm{d}-\mathrm{C}_{2 \mathrm{v}}$ & 2.483 & 0.200 & 3 & 6.660 & 2.276 & 4.384 & 2.486 & 2.725 \\
\hline & e- $D_{2 h}$ & 2.300 & 0.401 & 1 & 6.932 & 2.356 & 4.576 & 2.593 & 2.553 \\
\hline \multirow[t]{3}{*}{5} & a- $C_{4 v}$ & 2.829 & 0.901 & 1 & 7.269 & 2.262 & 5.007 & 2.770 & 2.631 \\
\hline & b- $C_{1}$ & 2.750 & 0.721 & 3 & 6.658 & 2.073 & 4.585 & 2.703 & 2.685 \\
\hline & c- $C_{1}$ & 2.687 & 0.527 & 1 & 6.896 & 2.144 & 4.752 & 2.680 & 2.649 \\
\hline \multirow[t]{5}{*}{6} & a- $C_{s}$ & 2.941 & 1.014 & 1 & 7.236 & 2.231 & 5.005 & 2.737 & 2.774 \\
\hline & b- $C_{s}$ & 2.856 & 0.366 & 3 & 6.273 & 1.802 & 4.471 & 2.749 & 2.812 \\
\hline & c- $\mathrm{C}_{1}$ & 2.796 & 0.630 & 3 & 6.397 & 1.695 & 4.702 & 2.744 & 2.804 \\
\hline & d- $C_{s}$ & 2.754 & 0.929 & 3 & 6.764 & 2.396 & 4.367 & 2.705 & 2.757 \\
\hline & e- $C_{2 v}$ & 2.704 & 0.334 & 3 & 6.849 & 2.557 & 4.292 & 2.759 & 2.661 \\
\hline \multirow[t]{6}{*}{7} & a- $C_{s}$ & 3.026 & 0.497 & 1 & 6.956 & 2.634 & 4.322 & 2.728 & 2.803 \\
\hline & b- $C_{s}$ & 2.992 & 0.837 & 1 & 6.711 & 1.773 & 4.938 & 2.724 & 2.752 \\
\hline & c- $C_{s}$ & 2.986 & 0.732 & 1 & 6.885 & 2.382 & 4.503 & 2.746 & 2.705 \\
\hline & d- $C_{2 v}$ & 2.924 & 0.737 & 3 & 6.356 & 1.899 & 4.457 & 2.740 & 2.641 \\
\hline & e- $C_{1}$ & 2.846 & 0.602 & 1 & 6.554 & 2.442 & 4.112 & 2.657 & 2.811 \\
\hline & $\mathrm{f}-\mathrm{C}_{\mathrm{s}}$ & 2.805 & 0.607 & 1 & 6.304 & 2.081 & 4.223 & 2.682 & 2.626 \\
\hline \multirow[t]{5}{*}{8} & a- $C_{2 v}$ & 3.113 & 0.852 & 1 & 6.811 & 2.582 & 4.229 & 2.759 & 2.834 \\
\hline & b- $\mathrm{C}_{1}$ & 3.022 & 0.908 & 3 & 6.890 & 2.495 & 4.395 & 2.648 & 2.805 \\
\hline & $\mathrm{c}-\mathrm{C}_{\mathrm{s}}$ & 3.008 & 0.627 & 1 & 6.454 & 2.294 & 4.160 & 2.737 & 2.767 \\
\hline & d- $C_{1}$ & 2.902 & 0.357 & 1 & 6.344 & 2.279 & 4.065 & 2.714 & 2.832 \\
\hline & e- $\mathrm{O}_{\mathrm{h}}$ & 2.776 & 0.460 & 3 & 7.041 & 2.854 & 4.187 & 3.001 & 2.599 \\
\hline \multirow[t]{7}{*}{9} & a- $\mathbf{C}_{1}$ & 3.069 & 0.551 & 1 & 6.770 & 2.535 & 4.235 & 2.745 & 2.860 \\
\hline & b- $C_{1}$ & 3.043 & 0.884 & 1 & 6.739 & 2.328 & 4.411 & 2.718 & 2.773 \\
\hline & c- $\mathrm{C}_{2}$ & 3.027 & 0.446 & 1 & 6.975 & 2.954 & 4.021 & 2.700 & 2.770 \\
\hline & d- $C_{2 v}$ & 3.018 & 0.418 & 1 & 6.266 & 2.105 & 4.161 & 2.747 & 2.811 \\
\hline & e- $C_{s}$ & 2.977 & 0.476 & 1 & 6.573 & 2.455 & 4.118 & 2.757 & 2.755 \\
\hline & f- $C_{1}$ & 2.971 & 0.723 & 1 & 6.401 & 2.113 & 4.288 & 2.762 & 2.784 \\
\hline & g- $C_{s}$ & 2.931 & 0.620 & 3 & 6.535 & 2.610 & 3.925 & 2.739 & 2.773 \\
\hline \multirow[t]{4}{*}{10} & a- $C_{2}$ & 3.164 & 0.529 & 1 & 7.016 & 2.874 & 4.142 & 2.846 & 2.870 \\
\hline & b- $C_{1}$ & 3.105 & 0.517 & 1 & 6.603 & 2.554 & 4.049 & 2.774 & 2.820 \\
\hline & c- $C_{s}$ & 3.042 & 0.663 & 1 & 6.550 & 2.364 & 4.186 & 2.796 & 2.725 \\
\hline & d- $C_{1}$ & 2.964 & 0.540 & 3 & 6.136 & 2.299 & 3.837 & 2.810 & 2.846 \\
\hline \multirow[t]{2}{*}{11} & a- $C_{2 v}$ & 3.149 & 0.463 & 1 & 6.950 & 3.012 & 3.938 & 2.805 & 2.806 \\
\hline & b- $C_{s}$ & 3.112 & 0.595 & 1 & 6.745 & 2.779 & 3.966 & 2.754 & 2.865 \\
\hline
\end{tabular}




\begin{tabular}{|c|c|c|c|c|c|c|c|c|c|}
\hline & c- $C_{s}$ & 3.064 & 0.799 & 1 & 6.324 & 1.734 & 4.590 & 2.714 & 2.729 \\
\hline & d- $\mathrm{C}_{1}$ & 3.035 & 0.647 & 1 & 6.386 & 2.037 & 4.349 & 2.791 & 2.748 \\
\hline & e- $C_{s}$ & 2.999 & 0.471 & 3 & 6.293 & 2.503 & 3.790 & 2.788 & 2.765 \\
\hline 12 & $a-D_{3 d}$ & 3.243 & 0.248 & 1 & 7.128 & 2.796 & 4.332 & 2.593 & 2.895 \\
\hline & b- $C_{s}$ & 3.240 & 0.438 & 1 & 7.127 & 3.276 & 3.851 & 2.778 & 2.908 \\
\hline & c- $\mathrm{C}_{1}$ & 3.177 & 0.601 & 1 & 6.774 & 3.012 & 3.762 & 2.744 & 2.885 \\
\hline & d- $C_{1}$ & 3.167 & 0.636 & 1 & 6.633 & 2.900 & 3.733 & 2.764 & 2.854 \\
\hline 13 & a- $C_{3 v}$ & 3.250 & 0.155 & 1 & 6.848 & 2.492 & 4.356 & 2.724 & 2.916 \\
\hline & b- $\mathrm{C}_{1}$ & 3.177 & 0.684 & 1 & 6.528 & 2.860 & 3.668 & 2.797 & 2.881 \\
\hline & c- $C_{1}$ & 3.177 & 0.603 & 1 & 6.548 & 2.940 & 3.608 & 2.697 & 2.842 \\
\hline & d- $C_{1}$ & 3.092 & 0.757 & 1 & 6.330 & 2.315 & 4.015 & 2.775 & 2.820 \\
\hline & e- $C_{4 v}$ & 3.012 & 0.496 & 1 & 6.504 & 2.713 & 3.791 & 2.764 & 2.663 \\
\hline 14 & a- $C_{2}$ & 3.309 & 0.354 & 1 & 7.095 & 2.973 & 4.122 & 2.769 & 2.970 \\
\hline & b- $\mathrm{O}_{\mathrm{h}}$ & 3.240 & 1.071 & 1 & 7.055 & 3.024 & 4.031 & 2.702 & 2.929 \\
\hline & c- $\mathrm{C}_{2 \mathrm{v}}$ & 3.082 & 0.500 & 3 & 6.552 & 2.871 & 3.681 & 2.809 & 2.726 \\
\hline & d- $C_{1}$ & 3.033 & 0.782 & 1 & 6.052 & 2.419 & 3.633 & 2.712 & 2.545 \\
\hline 15 & a- $C_{2 v}$ & 3.334 & 0.678 & 1 & 6.444 & 2.909 & $\mathbf{3 . 5 3 5}$ & 2.747 & 2.987 \\
\hline & b- $\mathrm{C}_{1}$ & 3.209 & 0.797 & 1 & 6.467 & 2.700 & 3.767 & 2.743 & 2.959 \\
\hline & c- $\mathrm{C}_{1}$ & 3.135 & 0.694 & 1 & 6.321 & 2.618 & 3.703 & 2.735 & 2.918 \\
\hline & d- $C_{1}$ & 3.032 & 0.650 & 3 & 6.330 & 2.716 & 3.614 & 2.787 & 2.773 \\
\hline 16 & a- $C_{1}$ & 3.304 & 0.708 & 1 & 6.315 & 2.847 & 3.468 & 2.750 & 3.008 \\
\hline & b- $C_{s}$ & 3.302 & 0.661 & 1 & 6.159 & 2.637 & 3.522 & 2.749 & 3.016 \\
\hline & c- $\mathrm{C}_{1}$ & 3.258 & 0.667 & 1 & 6.493 & 2.877 & 3.616 & 2.701 & 2.938 \\
\hline & d- $\mathrm{C}_{1}$ & 3.204 & 0.728 & 1 & 6.450 & 2.946 & 3.504 & 2.811 & 2.917 \\
\hline 17 & a- $\mathbf{C}_{1}$ & 3.265 & 0.558 & 1 & 6.012 & 2.580 & 3.432 & 2.762 & 2.948 \\
\hline & b- $C_{1}$ & 3.204 & 0.435 & 1 & 6.334 & 2.938 & 3.396 & 2.769 & 2.994 \\
\hline & c- $C_{1}$ & 3.166 & 0.574 & 1 & 6.301 & 2.943 & 3.358 & 2.753 & 2.853 \\
\hline & d- $C_{1}$ & 3.152 & 0.401 & 1 & 6.366 & 3.113 & 3.253 & 2.759 & 2.752 \\
\hline & e- $C_{s}$ & 3.059 & 0.436 & 1 & 6.170 & 2.546 & 3.624 & 2.713 & 2.781 \\
\hline 18 & a- $C_{s}$ & 3.245 & 0.312 & 1 & 6.101 & 2.796 & $\mathbf{3 . 3 0 5}$ & 2.684 & 2.973 \\
\hline & b- $C_{1}$ & 3.226 & 0.667 & 1 & 6.382 & 3.003 & 3.379 & 2.751 & 2.900 \\
\hline & c- $\mathrm{C}_{1}$ & 3.218 & 0.441 & 1 & 6.048 & 2.791 & 3.257 & 2.696 & 2.979 \\
\hline & d- $C_{s}$ & 3.191 & 0.698 & 1 & 6.221 & 2.943 & 3.278 & 2.673 & 2.906 \\
\hline 19 & a- $\mathbf{C}_{1}$ & 3.255 & 0.669 & 1 & 6.299 & 3.054 & 3.245 & 2.806 & 2.950 \\
\hline & b- $C_{1}$ & 3.254 & 0.629 & 1 & 6.564 & 3.067 & 3.497 & 2.730 & 2.978 \\
\hline & c- $\mathrm{C}_{1}$ & 3.251 & 0.580 & 1 & 6.557 & 3.019 & 3.538 & 2.749 & 2.970 \\
\hline & d- $C_{1}$ & 3.200 & 0.474 & 1 & 6.127 & 2.910 & 3.217 & 2.726 & 2.953 \\
\hline & e- $C_{1}$ & 3.185 & 0.733 & 1 & 6.225 & 2.882 & 3.343 & 2.717 & 2.872 \\
\hline
\end{tabular}


Table 2. Symmetry group, binding energy $E_{b}$ (eV/atom), HOMO-LUMO gap $\Delta E(e V)$, vertical ionization potential VIP $(\mathrm{eV})$, vertical electron affinity VEA $(\mathrm{eV})$, chemical hardness $\eta(\mathrm{eV})$ and average bond length $\mathrm{a}_{\mathrm{Ge}-\mathrm{Ge}}$ and $\mathrm{a}_{\mathrm{Ge}-\mathrm{Ta}}(\AA)$ for $\mathrm{TaGe}_{\mathrm{n}}$ clusters. Data for the lowestenergy isomer are in bold.

\begin{tabular}{|c|c|c|c|c|c|c|c|c|c|}
\hline $\mathbf{n}$ & $\begin{array}{c}\text { Label- } \\
\text { symmetry }\end{array}$ & $\begin{array}{c}E_{b} \\
\text { (eV/atom) }\end{array}$ & $\begin{array}{c}\Delta E \\
(\mathrm{eV})\end{array}$ & $\begin{array}{c}\mu \\
\left(\mu_{B}\right)\end{array}$ & $\begin{array}{l}\text { VIP } \\
(e V)\end{array}$ & $\begin{array}{l}\text { VEA } \\
(\mathrm{eV})\end{array}$ & $\begin{array}{c}\eta \\
(\mathrm{eV})\end{array}$ & $\begin{array}{l}\text { aGe- } \\
\text { Ge( }(\stackrel{\AA}{)})\end{array}$ & $\begin{array}{l}\text { aGe- } \\
\mathrm{Ta}(\stackrel{\AA}{\mathbf{A}})\end{array}$ \\
\hline 1 & a- $\mathbf{C}_{\infty \mathrm{v}}$ & 1.358 & 0.783 & 5 & 6.699 & 0.561 & 6.138 & - & 2.603 \\
\hline \multirow[t]{2}{*}{2} & a- $C_{2 v}$ & 2.329 & 1.376 & 3 & 7.005 & 1.007 & 5.998 & 2.453 & 2.579 \\
\hline & b- $D_{\infty \mathrm{h}}$ & 1.537 & 0.265 & 3 & 6.481 & 1.809 & 4.672 & - & 2.489 \\
\hline \multirow[t]{3}{*}{3} & a- $C_{s}$ & 2.646 & 0.345 & 1 & 7.185 & 1.716 & 5.469 & 2.781 & 2.523 \\
\hline & b- $\mathrm{C}_{2 \mathrm{v}}$ & 2.487 & 0.485 & 3 & 6.633 & 1.557 & 5.076 & 2.428 & 2.723 \\
\hline & c- $\mathrm{C}_{2 \mathrm{v}}$ & 2.178 & 0.149 & 3 & 6.702 & 2.071 & 4.631 & 2.500 & 2.558 \\
\hline \multirow[t]{4}{*}{4} & a- $C_{s}$ & 2.792 & 0.649 & 1 & 6.894 & 1.831 & 5.062 & 2.745 & 2.681 \\
\hline & b- $C_{2 v}$ & 2.709 & 0.604 & 1 & 6.913 & 1.859 & 5.054 & 2.494 & 2.674 \\
\hline & c- $\mathrm{C}_{1}$ & 2.626 & 0.476 & 3 & 6.436 & 1.746 & 4.690 & 2.693 & 2.703 \\
\hline & $\mathrm{d}-\mathrm{D}_{2 \mathrm{~h}}$ & 2.450 & 0.368 & 1 & 6.903 & 2.317 & 4.586 & 2.599 & 2.569 \\
\hline \multirow[t]{3}{*}{5} & a- $\mathbf{C}_{4 v}$ & 2.964 & 0.826 & 1 & 7.305 & 2.280 & 5.025 & 2.774 & 2.658 \\
\hline & b- $C_{1}$ & 2.905 & 0.443 & 1 & 6.880 & 2.208 & 4.672 & 2.669 & 2.767 \\
\hline & c- $\mathrm{C}_{\mathrm{s}}$ & 2.811 & 0.645 & 1 & 6.688 & 2.154 & 4.534 & 2.786 & 2.668 \\
\hline \multirow[t]{5}{*}{6} & a- $C_{s}$ & 3.054 & 0.898 & 1 & 7.297 & 2.400 & 4.897 & 2.741 & 2.770 \\
\hline & b- $\mathrm{C}_{\mathrm{s}}$ & 3.025 & 0.575 & 1 & 6.991 & 2.403 & 4.588 & 2.547 & 2.774 \\
\hline & c- $\mathrm{C}_{2 \mathrm{v}}$ & 2.966 & 0.810 & 1 & 6.604 & 2.112 & 4.492 & 2.745 & 2.740 \\
\hline & d- $C_{s}$ & 2.918 & 0.463 & 3 & 6.199 & 1.644 & 4.555 & 2.760 & 2.794 \\
\hline & e- $C_{1}$ & 2.894 & 0.607 & 3 & 6.829 & 2.640 & 4.189 & 2.706 & 2.736 \\
\hline \multirow[t]{5}{*}{7} & a- $C_{s}$ & 3.133 & 0.427 & 1 & 7.018 & 2.679 & 4.339 & 2.731 & 2.801 \\
\hline & b- $C_{s}$ & 3.097 & 0.703 & 1 & 6.764 & 2.315 & 4.449 & 2.748 & 2.719 \\
\hline & c- $\mathrm{C}_{\mathrm{s}}$ & 3.097 & 0.701 & 1 & 6.762 & 2.314 & 4.448 & 2.748 & 2.719 \\
\hline & d- $C_{2 v}$ & 3.019 & 0.666 & 1 & 6.126 & 1.701 & 4.425 & 2.737 & 2.652 \\
\hline & e- $C_{1}$ & 2.906 & 0.549 & 1 & 6.217 & 2.027 & 4.190 & 2.684 & 2.621 \\
\hline \multirow[t]{4}{*}{8} & a- $C_{2 v}$ & 3.221 & 0.841 & 1 & 6.787 & 2.570 & 4.217 & 2.763 & 2.839 \\
\hline & b- $C_{s}$ & 3.110 & 0.705 & 1 & 6.429 & 2.220 & 4.209 & 2.742 & 2.761 \\
\hline & c- $\mathrm{C}_{2}$ & 3.017 & 0.402 & 3 & 6.984 & 2.855 & 4.129 & 2.819 & 2.826 \\
\hline & d- $\mathrm{O}_{\mathrm{h}}$ & 2.879 & 0.451 & 3 & 7.018 & 2.851 & 4.167 & 3.020 & 2.615 \\
\hline \multirow[t]{6}{*}{9} & a- $C_{1}$ & 3.166 & 0.509 & 1 & 6.748 & 2.537 & 4.211 & 2.747 & 2.862 \\
\hline & b- $C_{1}$ & 3.130 & 0.784 & 1 & 6.663 & 2.404 & 4.259 & 2.722 & 2.773 \\
\hline & c- $\mathrm{C}_{2}$ & 3.125 & 0.439 & 1 & 6.954 & 2.968 & 3.986 & 2.701 & 2.779 \\
\hline & d- $C_{2 v}$ & 3.103 & 0.293 & 1 & 6.155 & 2.257 & 3.898 & 2.767 & 2.835 \\
\hline & e- $C_{1}$ & 3.044 & 0.629 & 1 & 6.230 & 2.029 & 4.201 & 2.766 & 2.777 \\
\hline & f- $C_{s}$ & 3.020 & 0.909 & 3 & 6.323 & 2.158 & 4.165 & 2.811 & 2.720 \\
\hline \multirow[t]{4}{*}{10} & a- $C_{2}$ & 3.256 & 0.494 & 1 & 7.084 & 2.877 & 4.207 & 2.833 & 2.875 \\
\hline & b- $C_{s}$ & 3.114 & 0.596 & 1 & 6.617 & 2.440 & 4.066 & 2.798 & 2.724 \\
\hline & c- $\mathrm{C}_{\mathrm{s}}$ & 3.095 & 0.360 & 1 & 6.506 & 2.684 & 3.933 & 2.768 & 2.680 \\
\hline & d- $C_{1}$ & 3.090 & 0.431 & 1 & 6.213 & 2.348 & 3.865 & 2.720 & 2.772 \\
\hline \multirow[t]{5}{*}{11} & a- $\mathbf{C}_{2}$ & 3.272 & 0.527 & 1 & 6.875 & 3.071 & 3.804 & 2.715 & 2.904 \\
\hline & b- $C_{s}$ & 3.255 & 0.682 & 1 & 6.666 & 2.886 & 3.780 & 2.672 & 2.844 \\
\hline & c- $\mathrm{C}_{\mathrm{s}}$ & 3.172 & 0.570 & 1 & 6.342 & 2.379 & 3.963 & 2.756 & 2.822 \\
\hline & d- $C_{1}$ & 3.155 & 0.565 & 1 & 6.347 & 2.415 & 3.932 & 2.705 & 2.843 \\
\hline & e- $C_{s}$ & 3.127 & 0.761 & 1 & 6.150 & 2.034 & 4.116 & 2.719 & 2.733 \\
\hline 12 & a- $\mathbf{D}_{3 \mathrm{dd}}$ & 3.323 & 0.260 & 1 & 7.124 & 2.827 & 4.297 & 2.594 & 2.898 \\
\hline
\end{tabular}




\begin{tabular}{|c|c|c|c|c|c|c|c|c|c|}
\hline & b- $C_{s}$ & 3.319 & 0.420 & 1 & 7.067 & 3.258 & 3.809 & 2.794 & 2.909 \\
\hline & c- $\mathrm{C}_{2}$ & 3.278 & 0.647 & 1 & 6.740 & 2.977 & 3.763 & 2.736 & 2.846 \\
\hline & d- $\mathrm{C}_{1}$ & 3.247 & 0.645 & 1 & 6.624 & 2.901 & 3.723 & 2.765 & 2.861 \\
\hline & e- $C_{1}$ & 3.163 & 0.609 & 1 & 6.361 & 2.668 & 3.693 & 2.783 & 2.804 \\
\hline 13 & a- $C_{3 v}$ & 3.321 & 0.563 & 1 & 6.824 & 2.497 & 4.327 & 2.727 & 2.920 \\
\hline & a- $C_{1}$ & 3.252 & 0.683 & 1 & 6.528 & 2.886 & 3.642 & 2.786 & 2.855 \\
\hline & c- $\mathrm{C}_{1}$ & 3.250 & 0.600 & 1 & 6.511 & 2.935 & 3.576 & 2.716 & 2.849 \\
\hline & d- $\mathrm{C}_{1}$ & 3.246 & 0.499 & 1 & 6.548 & 2.944 & 3.604 & 2.739 & 2.847 \\
\hline & e- $C_{1}$ & 3.156 & 0.760 & 1 & 6.283 & 2.437 & 3.846 & 2.777 & 2.817 \\
\hline & f- $C_{1}$ & 3.133 & 0.537 & 1 & 6.531 & 2.718 & 3.813 & 2.793 & 2.678 \\
\hline 14 & a- $C_{2}$ & 3.381 & 0.345 & 1 & 7.106 & 2.952 & 4.154 & 2.772 & 2.974 \\
\hline & b- $C_{1}$ & 3.364 & 0.649 & 1 & 6.887 & 3.244 & 3.643 & 2.723 & 2.979 \\
\hline & c- $\mathrm{O}_{\mathrm{h}}$ & 3.301 & 0.976 & 3 & 7.016 & 3.102 & 3.914 & 2.707 & 2.932 \\
\hline & d- $\mathrm{C}_{1}$ & 3.087 & 0.686 & 1 & 5.985 & 2.527 & 3.458 & 2.743 & 2.558 \\
\hline 15 & a- $C_{2 v}$ & 3.401 & 0.687 & 1 & 6.441 & 2.910 & 3.531 & 2.749 & 2.990 \\
\hline & b- $C_{1}$ & 3.319 & 0.532 & 1 & 6.383 & 2.958 & 3.425 & 2.678 & 2.947 \\
\hline & c- $\mathrm{C}_{1}$ & 3.243 & 0.524 & 1 & 6.127 & 2.476 & 3.651 & 2.753 & 2.903 \\
\hline & d- $C_{1}$ & 3.141 & 0.833 & 1 & 6.358 & 2.659 & 3.699 & 2.765 & 2.735 \\
\hline 16 & a- $C_{s}$ & 3.365 & 0.707 & 1 & 6.170 & 2.652 & 3.518 & 2.750 & 3.019 \\
\hline & b- $C_{1}$ & 3.331 & 0.642 & 1 & 6.551 & 3.066 & 3.485 & 2.634 & 2.896 \\
\hline & c- $\mathrm{C}_{1}$ & 3.265 & 0.697 & 1 & 6.419 & 2.965 & 3.454 & 2.814 & 2.922 \\
\hline & d- $\mathrm{C}_{1}$ & 3.143 & 0.450 & 1 & 6.169 & 2.773 & 3.396 & 2.752 & 2.876 \\
\hline 17 & a- $C_{1}$ & 3.323 & 0.592 & 1 & 6.037 & 2.601 & 3.436 & 2.760 & 2.961 \\
\hline & b- $\mathrm{C}_{1}$ & 3.262 & 0.448 & 1 & 6.330 & 2.966 & 3.364 & 2.769 & 2.980 \\
\hline & c- $\mathrm{C}_{1}$ & 3.223 & 0.572 & 1 & 6.286 & 2.951 & 3.335 & 2.755 & 2.861 \\
\hline & d- $C_{1}$ & 3.209 & 0.547 & 1 & 6.393 & 3.090 & 3.303 & 2.745 & 2.777 \\
\hline & e- $C_{s}$ & 3.107 & 0.365 & 1 & 6.061 & 2.679 & 3.382 & 2.714 & 2.782 \\
\hline 18 & a- $C_{1}$ & 3.279 & 0.608 & 1 & 6.357 & $\mathbf{3 . 0 3 7}$ & 3.320 & 2.741 & 2.905 \\
\hline & b- $C_{2 v}$ & 3.250 & 0.410 & 1 & 6.134 & 2.909 & 3.225 & 2.616 & 2.948 \\
\hline & c- $C_{s}$ & 3.246 & 0.706 & 1 & 6.220 & 2.956 & 3.264 & 2.673 & 2.911 \\
\hline & d- $\mathrm{C}_{2}$ & 3.233 & 0.526 & 1 & 6.443 & 3.149 & 3.294 & 2.776 & 2.851 \\
\hline & e- $C_{s}$ & 3.138 & 0.538 & 1 & 5.967 & 2.584 & 3.383 & 2.810 & 2.657 \\
\hline & f- $C_{1}$ & 3.114 & 0.531 & 1 & 6.117 & 2.938 & 3.179 & 2.738 & 2.778 \\
\hline 19 & a- $C_{1}$ & 3.308 & 0.463 & 1 & 6.500 & 3.161 & 3.339 & 2.696 & 3.009 \\
\hline & b- $\mathrm{C}_{1}$ & 3.265 & 0.523 & 1 & 6.302 & 2.982 & 3.320 & 2.756 & 3.003 \\
\hline & c- $\mathrm{C}_{1}$ & 3.260 & 0.477 & 1 & 6.328 & 3.036 & 3.292 & 2.707 & 2.992 \\
\hline & d- $C_{s}$ & 3.235 & 0.700 & 1 & 6.214 & 2.934 & 3.280 & 2.703 & 2.876 \\
\hline & e- $C_{s}$ & 3.223 & 0.271 & 1 & 6.279 & 3.055 & 3.224 & 2.738 & 2.950 \\
\hline
\end{tabular}


Graphical Abstract

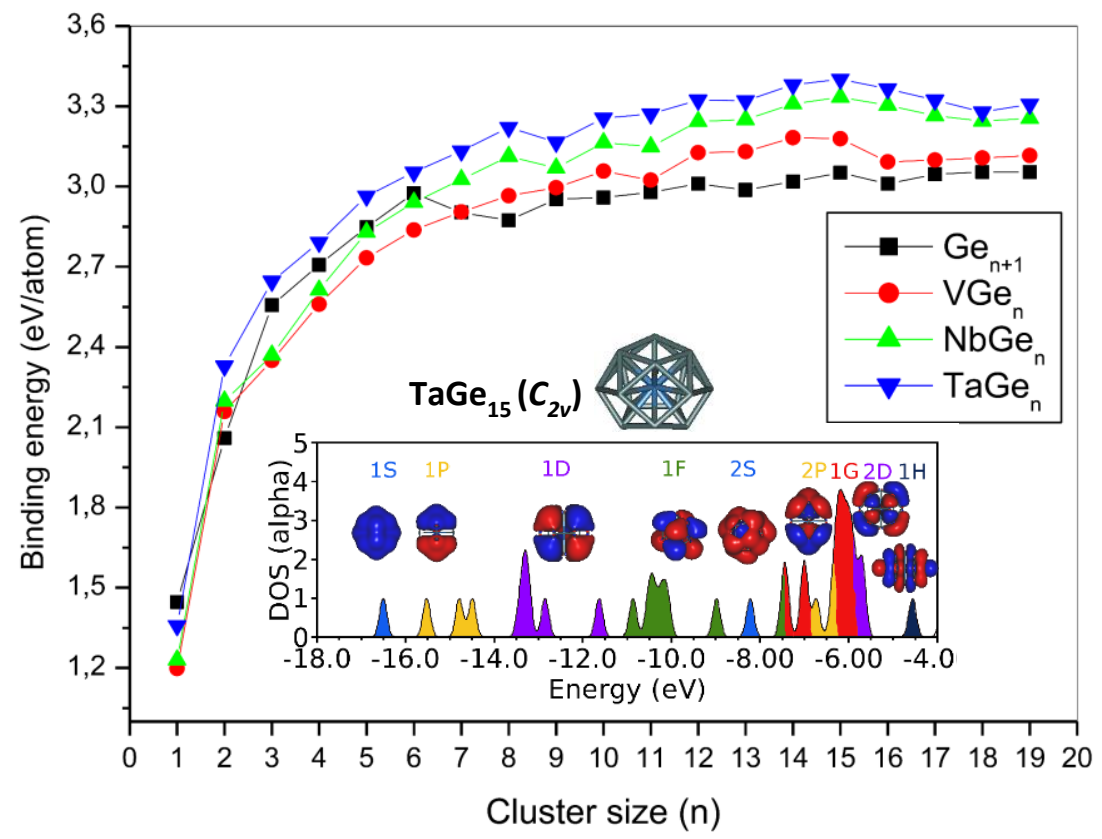




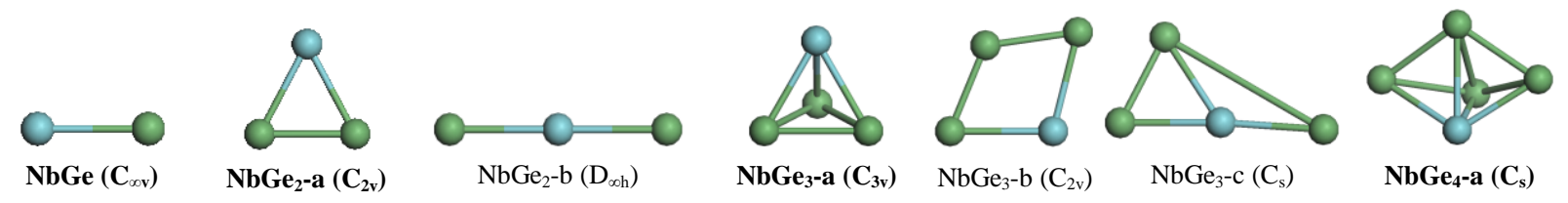

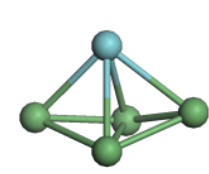

$\mathrm{NbGe}_{4}-\mathrm{b}\left(\mathrm{C}_{2}\right)$

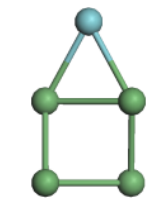

$\mathrm{NbGe}_{4}-\mathrm{c}\left(\mathrm{C}_{2}\right)$

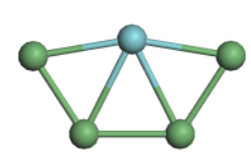

$\mathrm{NbGe}_{4}-\mathrm{d}\left(\mathrm{C}_{2 v}\right)$

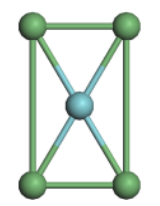

$\mathrm{NbGe}_{4}-\mathrm{e}\left(\mathrm{D}_{2 \mathrm{~h}}\right)$

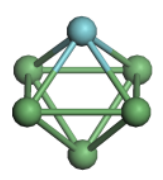

$\mathrm{NbGe}_{5}-\mathbf{a}\left(\mathrm{C}_{4 \mathrm{v}}\right)$

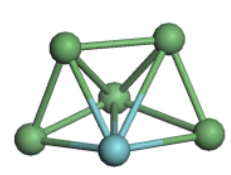

$\mathrm{NbGe}_{5}-\mathrm{b}\left(\mathrm{C}_{1}\right)$

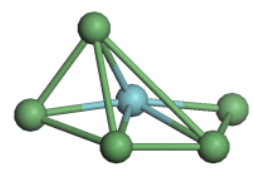

$\mathrm{NbGe}_{5}-\mathrm{c}\left(\mathrm{C}_{1}\right)$

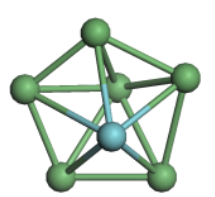

$\mathrm{NbGe}_{6}-\mathbf{a}\left(\mathrm{C}_{\mathrm{s}}\right)$

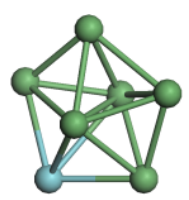

$\mathrm{NbGe}_{6}-\mathrm{b}\left(\mathrm{C}_{\mathrm{s}}\right)$

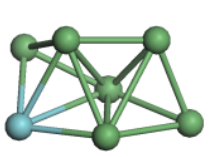

$\mathrm{NbGe}_{6}-\mathrm{c}\left(\mathrm{C}_{1}\right)$

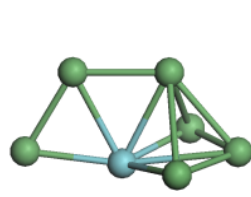

$\mathrm{NbGe}_{6}-\mathrm{d}\left(\mathrm{C}_{\mathrm{s}}\right)$

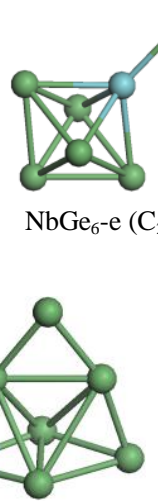

$\mathrm{NbGe}_{7}-\mathrm{f}\left(\mathrm{C}_{\mathrm{s}}\right)$

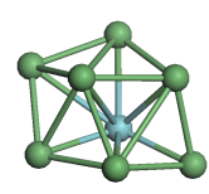

$\mathrm{NbGe}_{7}-\mathbf{a}\left(\mathrm{C}_{\mathrm{s}}\right)$

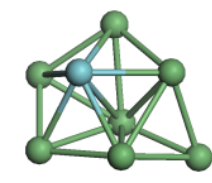

$\mathrm{NbGe}_{7}-\mathrm{b}\left(\mathrm{C}_{\mathrm{s}}\right)$

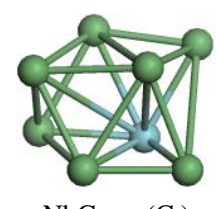

$\mathrm{NbGe}_{7}-\mathrm{c}\left(\mathrm{C}_{\mathrm{s}}\right)$

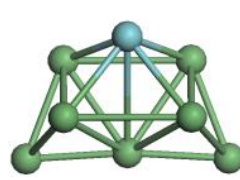

$\mathrm{NbGe}_{7}-\mathrm{d}\left(\mathrm{C}_{2 \mathrm{v}}\right)$

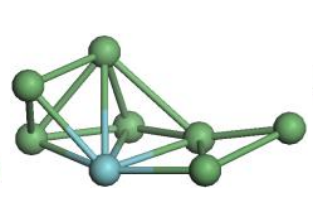

$\mathrm{NbGe}_{7}-\mathrm{e}\left(\mathrm{C}_{1}\right)$
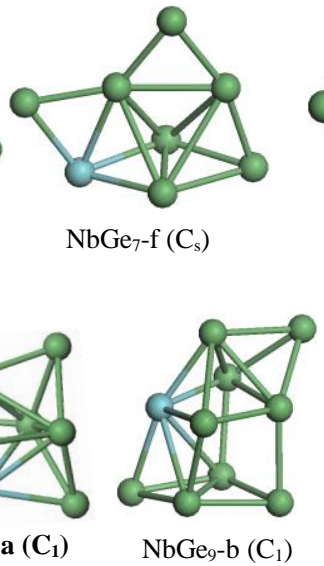

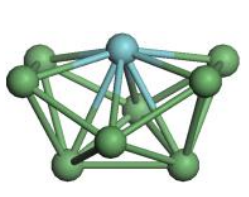

$\mathrm{NbGe}_{8}-\mathbf{a}\left(\mathrm{C}_{2 \mathrm{v}}\right)$

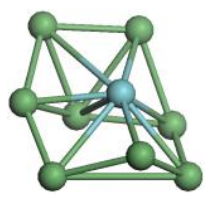

$\mathrm{NbGe}_{8}-\mathrm{b}\left(\mathrm{C}_{1}\right)$

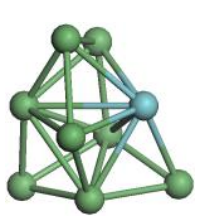

$\mathrm{NbGe}_{8}-\mathrm{c}\left(\mathrm{C}_{\mathrm{s}}\right)$

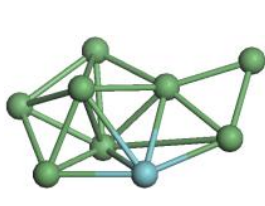

$\mathrm{NbGe}_{8}-\mathrm{d}\left(\mathrm{C}_{1}\right)$
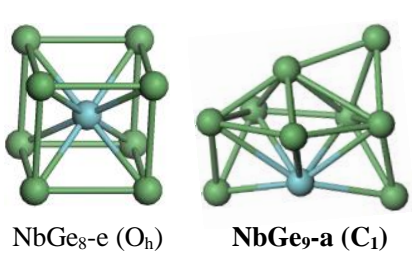

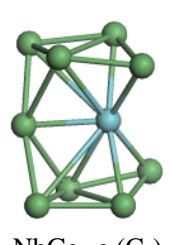

$\mathrm{NbGe}_{9}-\mathrm{c}\left(\mathrm{C}_{2}\right)$

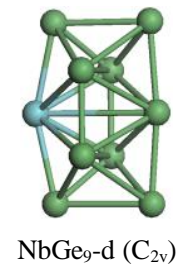

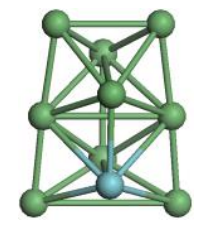

$\mathrm{NbGe}_{9}-\mathrm{e}\left(\mathrm{C}_{\mathrm{s}}\right)$

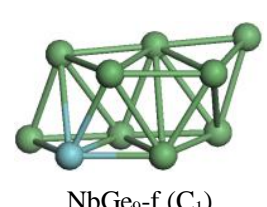

$\mathrm{NbGe}_{9}-\mathrm{f}\left(\mathrm{C}_{1}\right)$

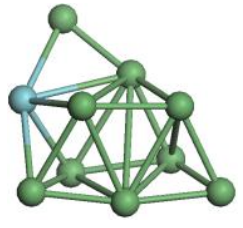

$\mathrm{NbGe}_{9}-\mathrm{g}\left(\mathrm{C}_{\mathrm{s}}\right)$

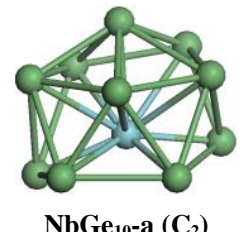

$\mathrm{NbGe}_{10}$-a $\left(\mathrm{C}_{2}\right)$

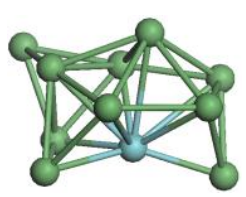

$\mathrm{NbGe}_{10}-\mathrm{b}\left(\mathrm{C}_{1}\right)$

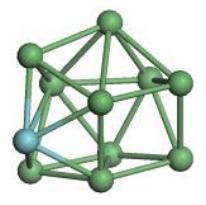

$\mathrm{NbGe}_{10}-\mathrm{c}\left(\mathrm{C}_{\mathrm{s}}\right)$

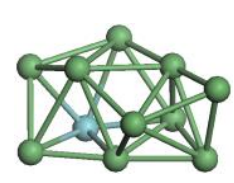

$\mathrm{NbGe}_{10}-\mathrm{d}\left(\mathrm{C}_{1}\right)$

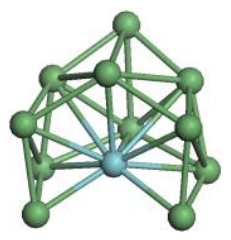

$\mathrm{NbGe}_{11-a}\left(\mathrm{C}_{2 \mathrm{v}}\right)$

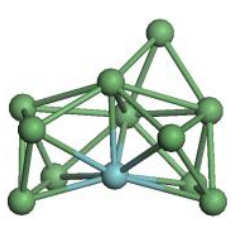

$\mathrm{NbGe}_{11}-\mathrm{b}\left(\mathrm{C}_{\mathrm{s}}\right)$

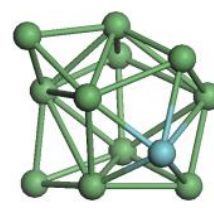

$\mathrm{NbGe}_{11}-\mathrm{c}\left(\mathrm{C}_{\mathrm{s}}\right)$

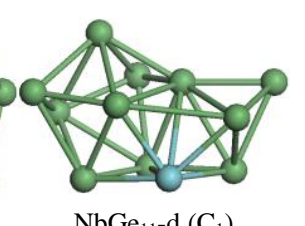

$\mathrm{NbGe}_{11}-\mathrm{d}\left(\mathrm{C}_{1}\right)$

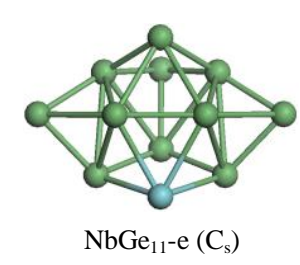




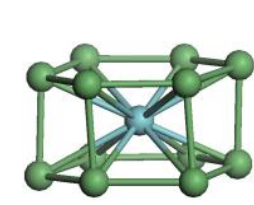

$\mathrm{NbGe}_{12}-\mathbf{a}\left(\mathrm{D}_{3 \mathrm{~d}}\right)$
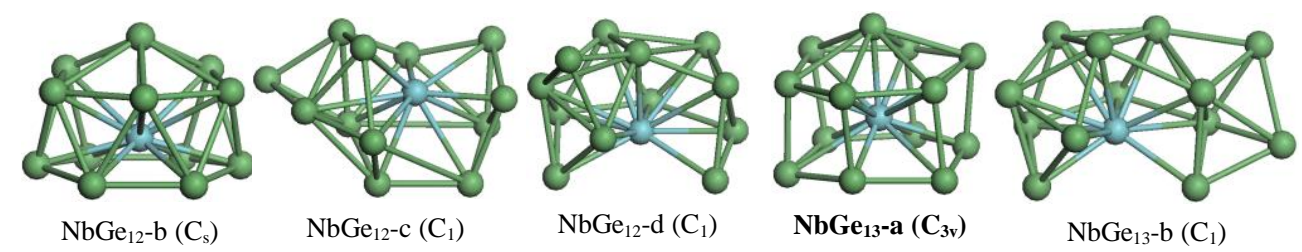

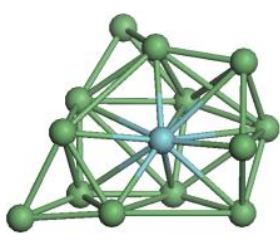

$\mathrm{NbGe}_{13}-\mathrm{c}\left(\mathrm{C}_{1}\right)$

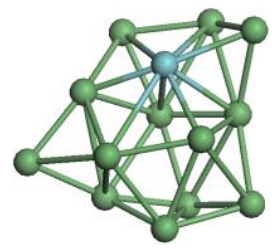

$\mathrm{NbGe}_{13}-\mathrm{d}\left(\mathrm{C}_{1}\right)$

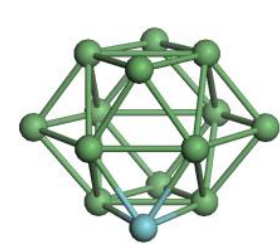

$\mathrm{NbGe}_{13}-\mathrm{e}\left(\mathrm{C}_{4 \mathrm{v}}\right)$
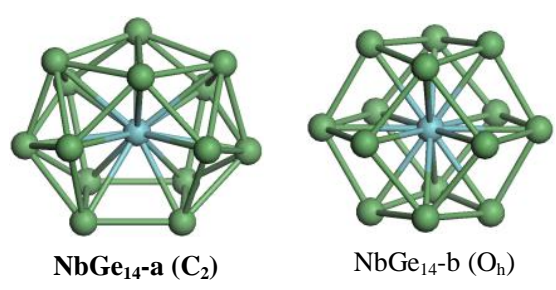

$\mathrm{NbGe}_{14}-\mathrm{b}\left(\mathrm{O}_{\mathrm{h}}\right)$

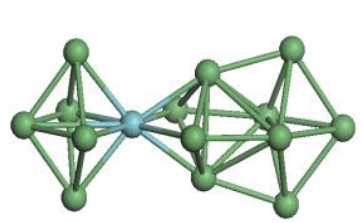

$\mathrm{NbGe}_{14}-\mathrm{c}\left(\mathrm{C}_{2 \mathrm{v}}\right)$

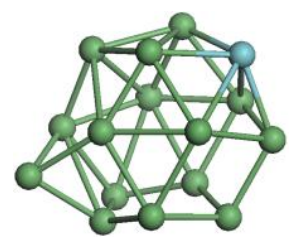

$\mathrm{NbGe}_{15}-\mathrm{d}\left(\mathrm{C}_{1}\right)$

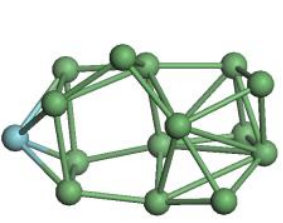

$\mathrm{NbGe}_{14}-\mathrm{d}\left(\mathrm{C}_{1}\right)$

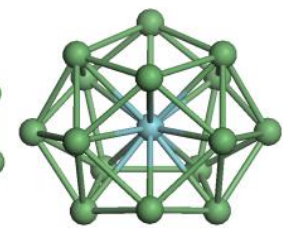

$\mathrm{NbGe}_{15}-\mathrm{a}\left(\mathrm{C}_{2 \mathrm{v}}\right)$
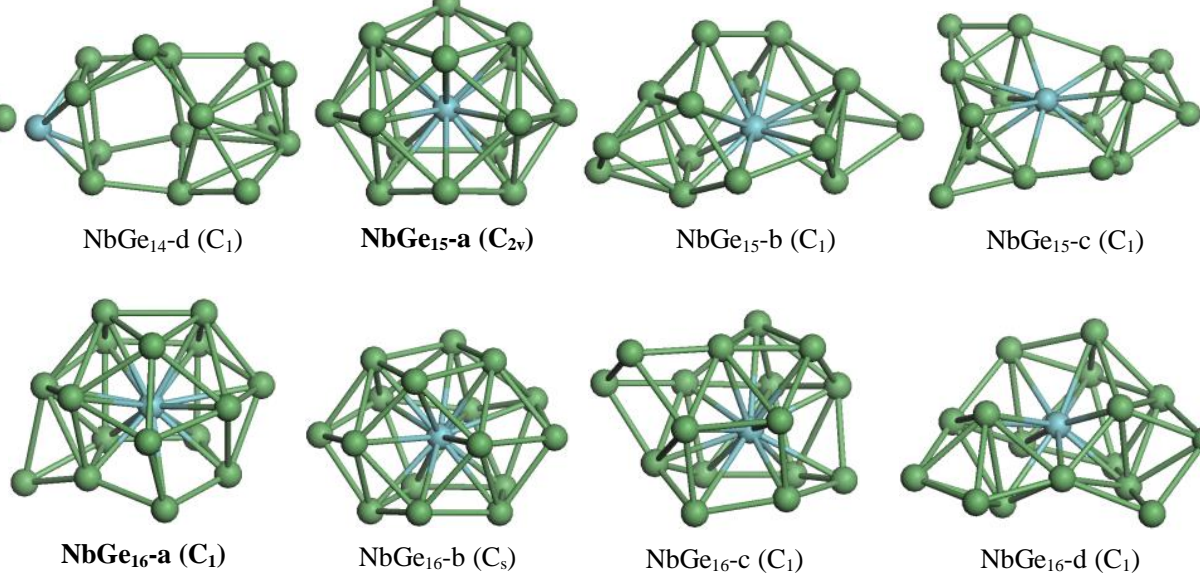

$\mathrm{NbGe}_{16}-\mathrm{c}\left(\mathrm{C}_{1}\right)$
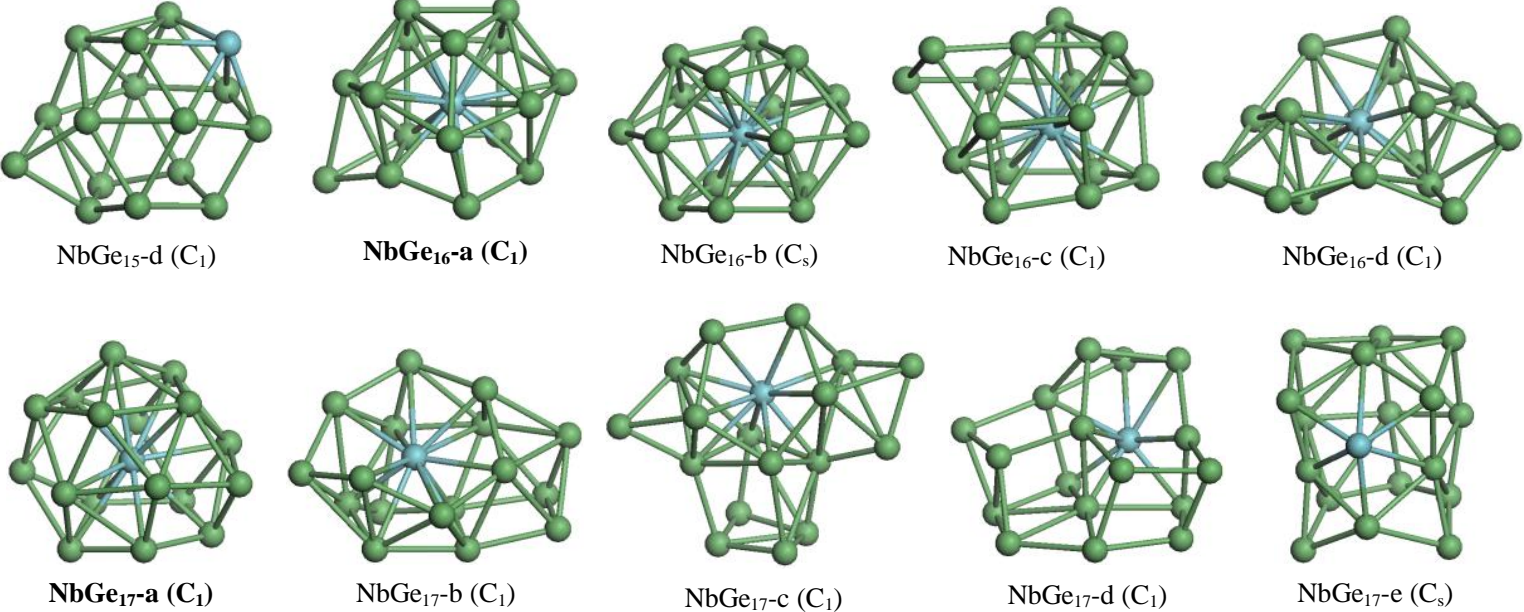

$\mathrm{NbGe}_{17}-\mathrm{c}\left(\mathrm{C}_{1}\right)$
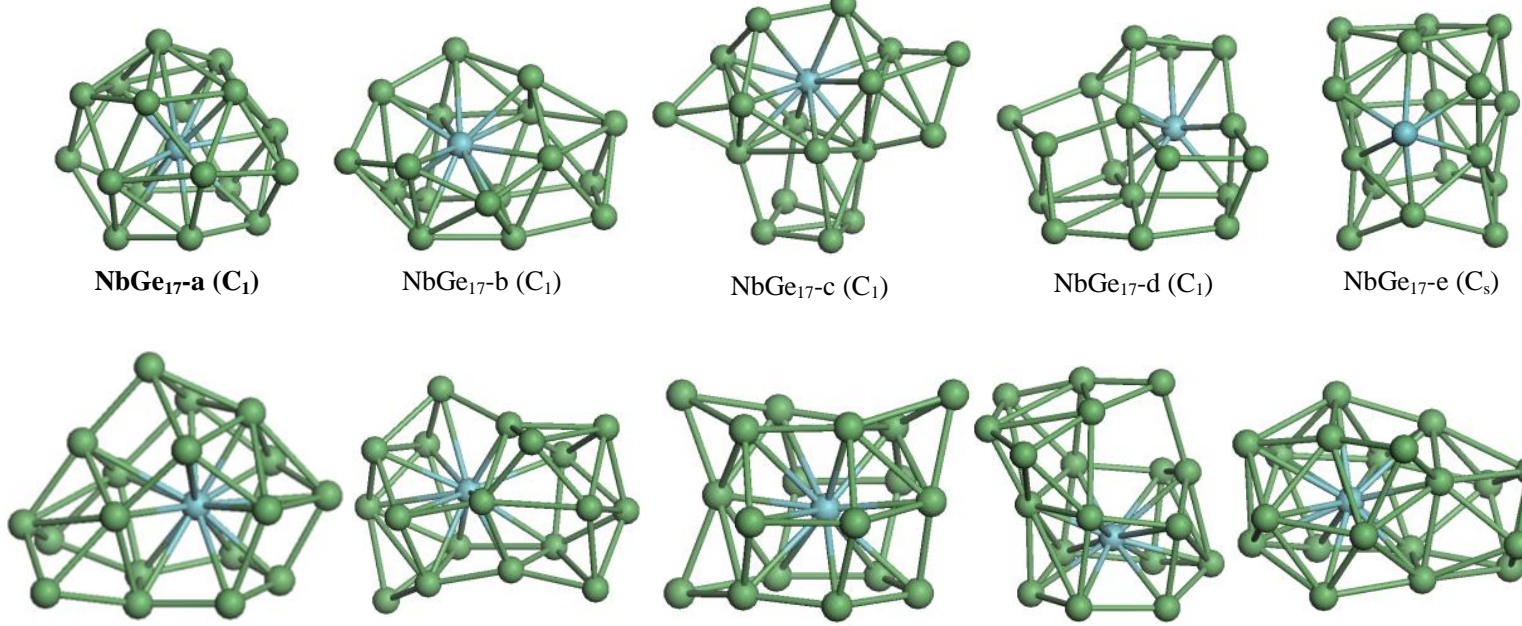

$\mathrm{NbGe}_{18}-\mathrm{b}\left(\mathrm{C}_{1}\right)$

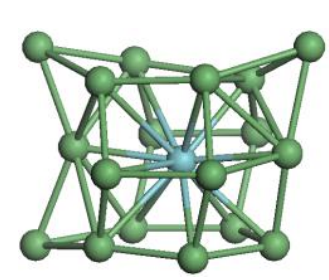

$\mathrm{NbGe}_{18}-\mathrm{c}\left(\mathrm{C}_{1}\right)$

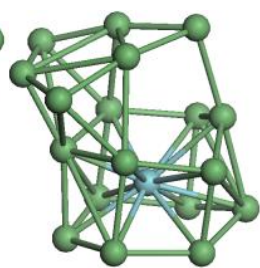

$\mathrm{NbGe}_{18}-\mathrm{d}\left(\mathrm{C}_{\mathrm{s}}\right)$
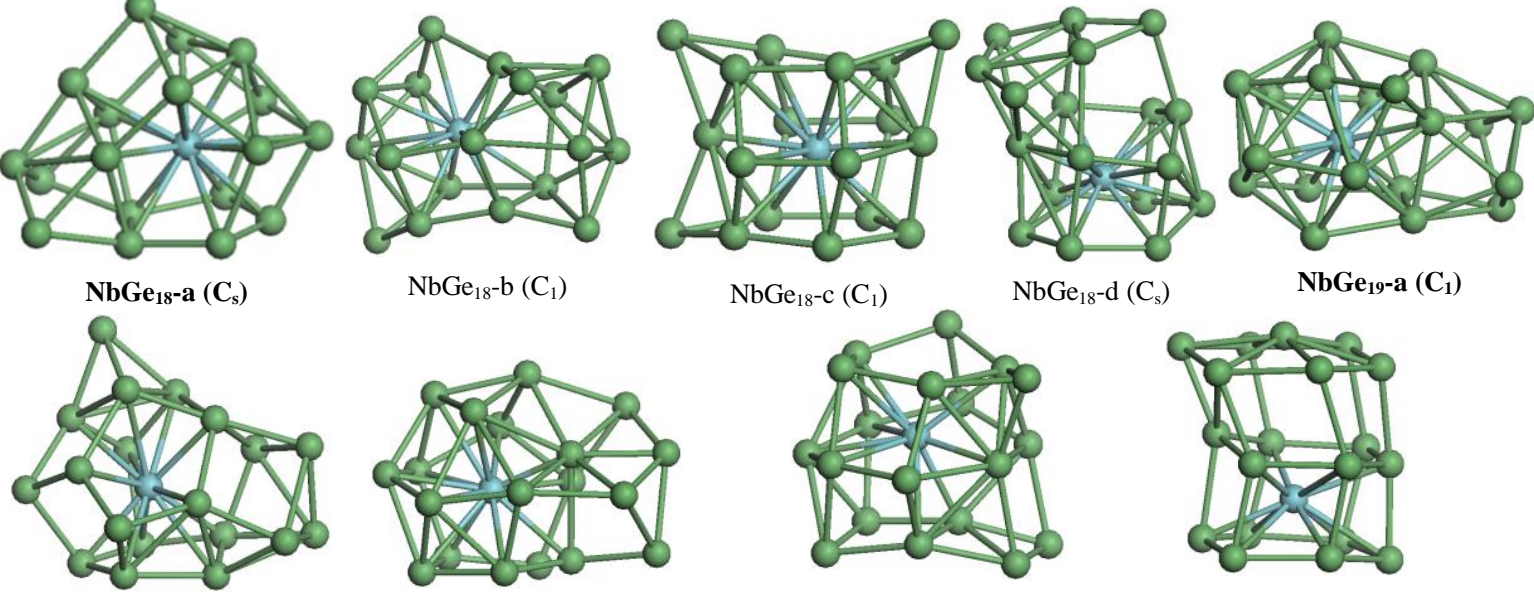

$\mathrm{NbGe}_{19}-\mathrm{c}\left(\mathrm{C}_{1}\right)$

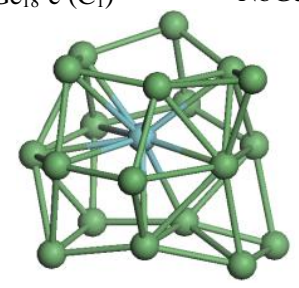

$\mathrm{NbGe}_{19}-\mathrm{d}\left(\mathrm{C}_{1}\right)$

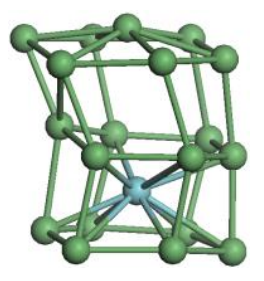

$\mathrm{NbGe}_{19}$-e $\left(\mathrm{C}_{1}\right)$

Figure 1. Lowest-energy structures and their corresponding isomers of $\mathrm{NbGe}_{\mathrm{n}}(\mathrm{n}=1-19)$ clusters. For each size, the lowest-energy isomer is indicated in bold. 

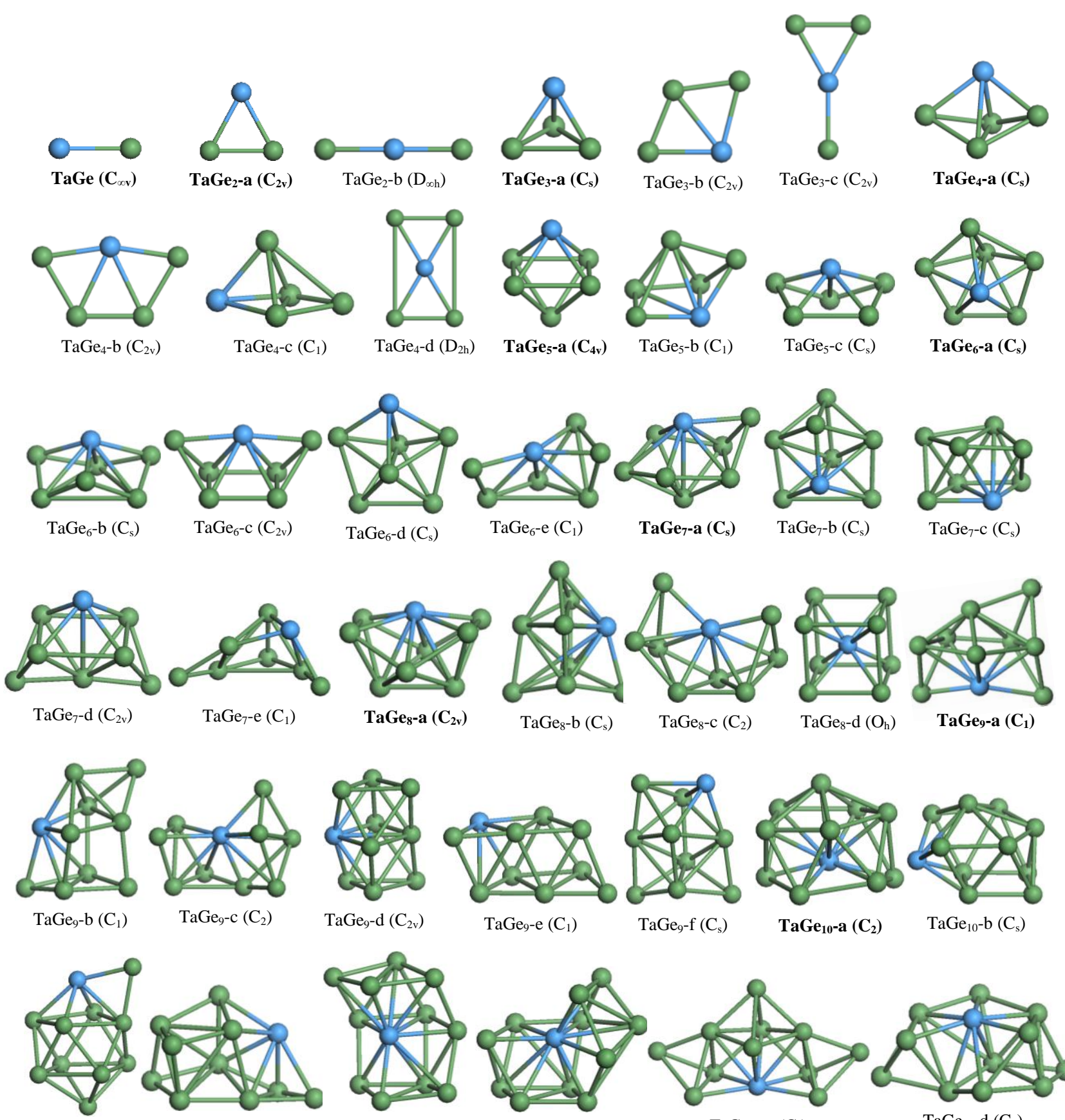

$\mathrm{TaGe}_{10}-\mathrm{c}\left(\mathrm{C}_{\mathrm{s}}\right)$

TaGe $_{11}-\mathbf{a}\left(C_{2}\right)$

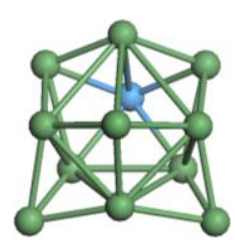

$\mathrm{TaGe}_{11}$-e $\left(\mathrm{C}_{\mathrm{s}}\right)$

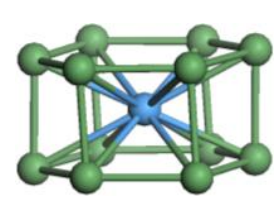

TaGe $_{12}-\mathbf{a}\left(D_{3 d}\right)$

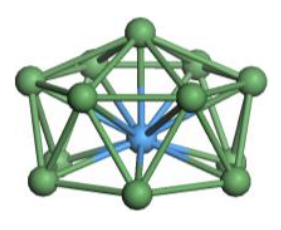

$\mathrm{TaGe}_{12}-\mathrm{b}\left(\mathrm{C}_{\mathrm{s}}\right)$

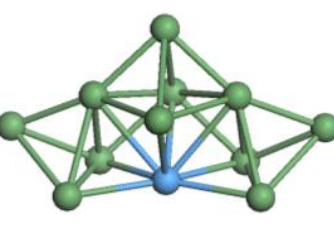

$\mathrm{TaGe}_{11}-\mathrm{c}\left(\mathrm{C}_{\mathrm{s}}\right)$
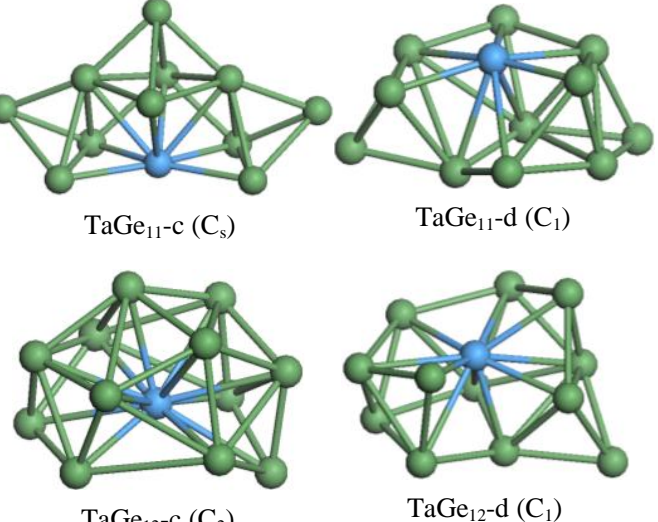

$\mathrm{TaGe}_{12}-\mathrm{d}\left(\mathrm{C}_{1}\right)$

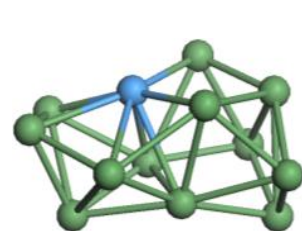

$\mathrm{TaGe}_{12}$-e $\left(\mathrm{C}_{1}\right)$

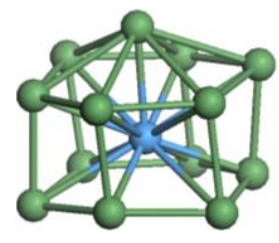

$\mathrm{TaGe}_{13}-\mathrm{a}\left(\mathrm{C}_{3 \mathrm{v}}\right)$

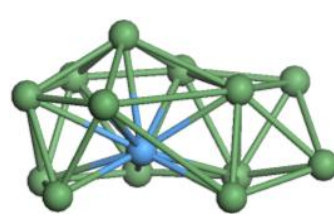

$\mathrm{TaGe}_{13}-\mathrm{b}\left(\mathrm{C}_{1}\right)$

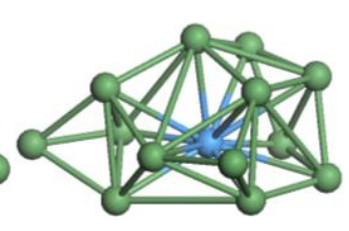

$\mathrm{TaGe}_{13}-\mathrm{c}\left(\mathrm{C}_{1}\right)$

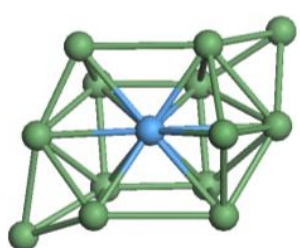

$\mathrm{TaGe}_{13}-\mathrm{d}\left(\mathrm{C}_{1}\right)$ 


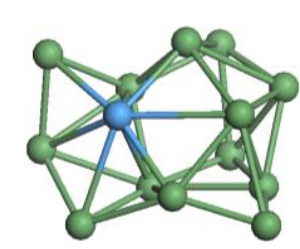

$\mathrm{TaGe}_{13}$-e $\left(\mathrm{C}_{1}\right)$

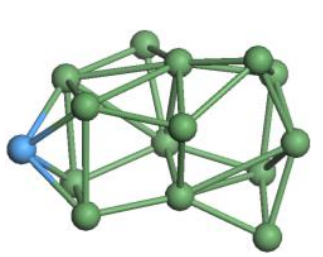

$\mathrm{TaGe}_{14}-\mathrm{d}\left(\mathrm{C}_{1}\right)$

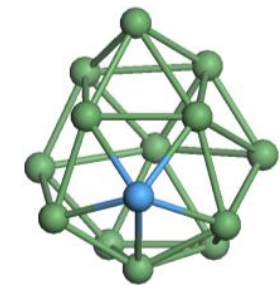

$\mathrm{TaGe}_{13}-\mathrm{f}\left(\mathrm{C}_{1}\right)$
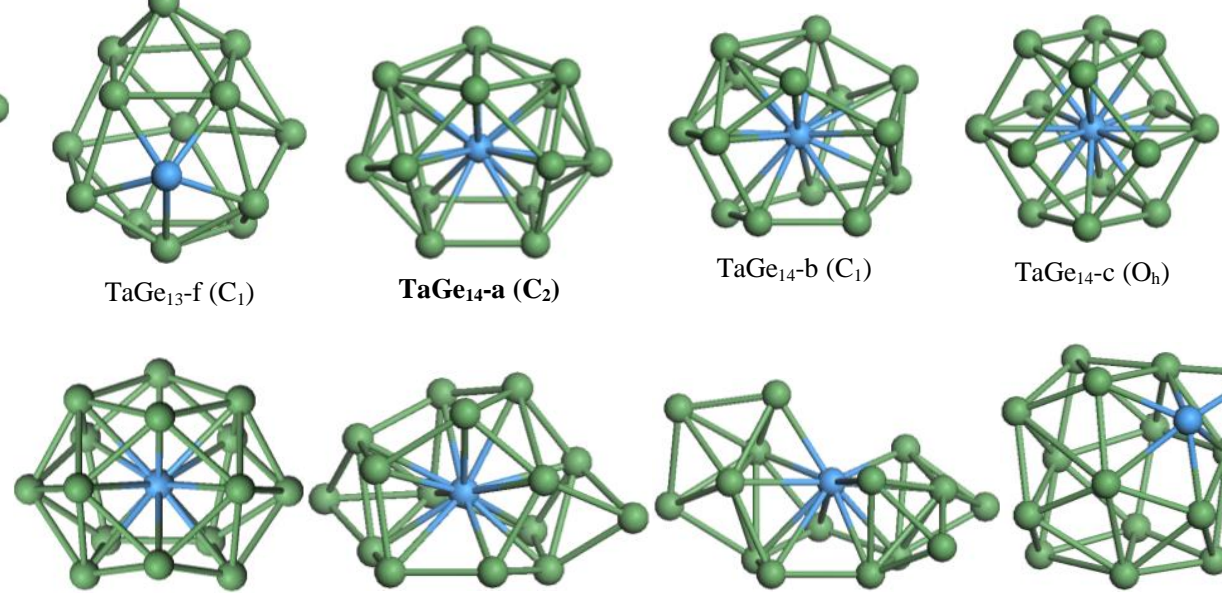

$\mathrm{TaGe}_{15}-\mathrm{b}\left(\mathrm{C}_{1}\right)$
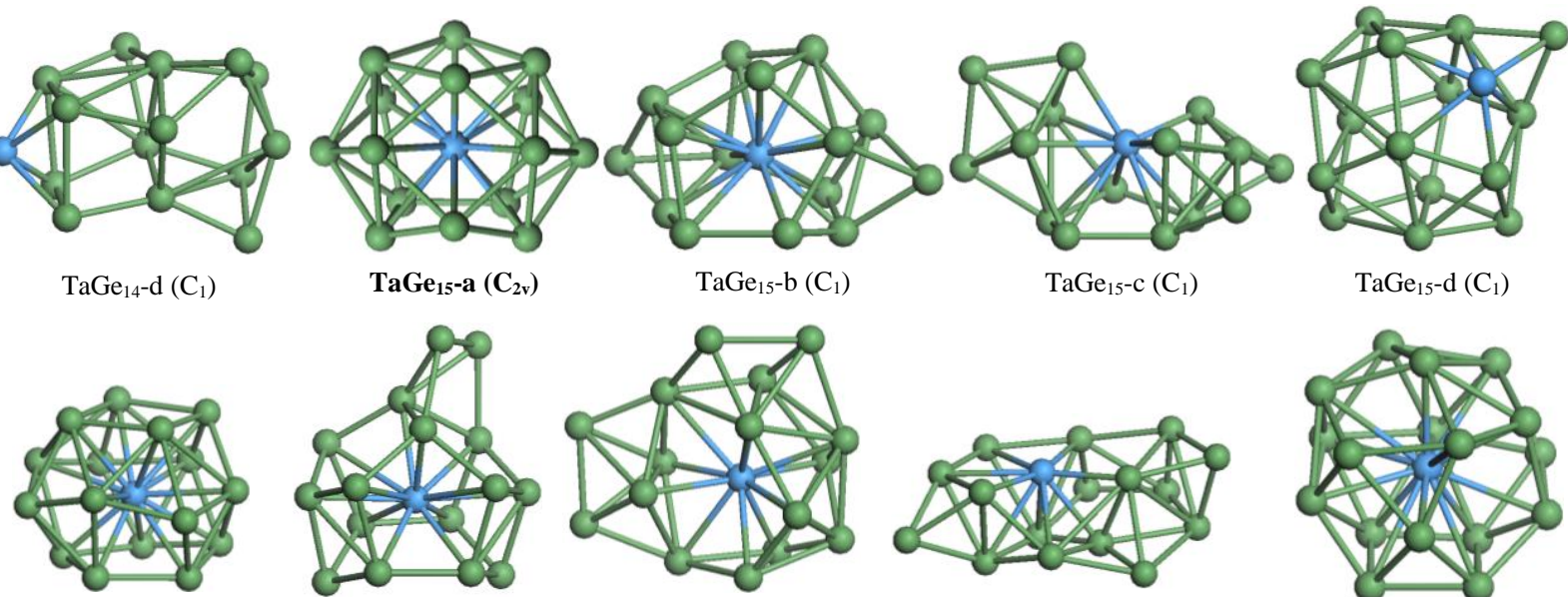

TaGe $_{16-a}\left(C_{s}\right)$
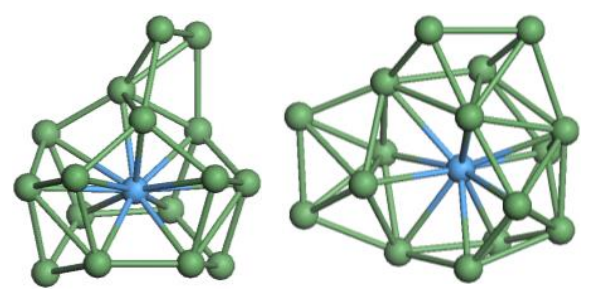

$\mathrm{TaGe}_{16}-\mathrm{c}\left(\mathrm{C}_{1}\right)$

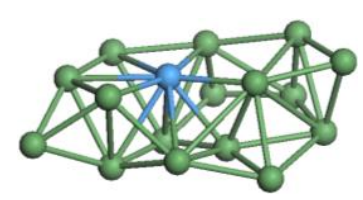

$\mathrm{TaGe}_{16}-\mathrm{d}\left(\mathrm{C}_{1}\right)$

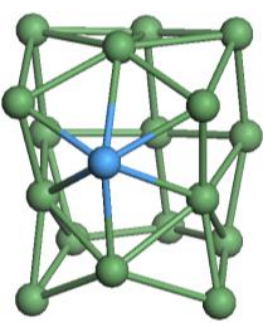

$\mathrm{TaGe}_{17}-\mathrm{e}\left(\mathrm{C}_{\mathrm{s}}\right)$

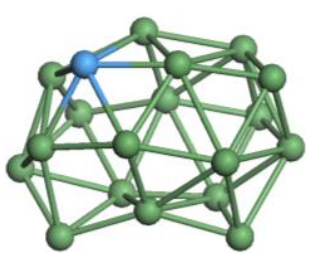

$\mathrm{TaGe}_{18} \mathrm{e}\left(\mathrm{C}_{\mathrm{s}}\right)$

$\mathrm{TaGe}_{18}-\mathrm{d}\left(\mathrm{C}_{2}\right)$

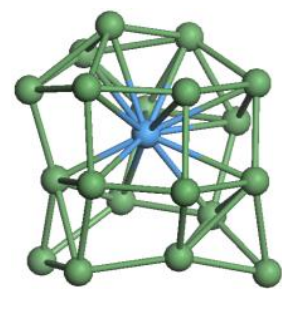

$\mathrm{TaGe}_{19}-\mathrm{c}\left(\mathrm{C}_{1}\right)$

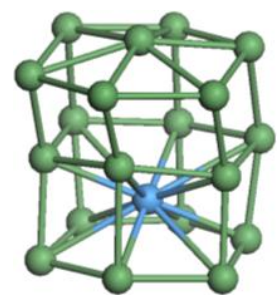

$\mathrm{TaGe}_{19}-\mathrm{d}\left(\mathrm{C}_{\mathrm{s}}\right)$

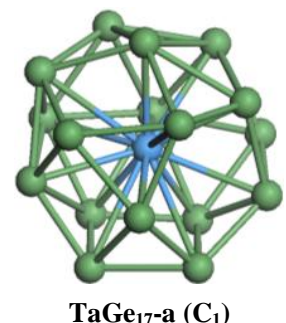

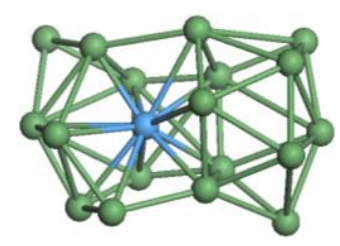

TaGe $_{18-a}\left(C_{1}\right)$

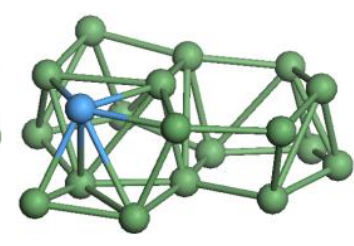

$\mathrm{TaGe}_{18}-\mathrm{f}\left(\mathrm{C}_{1}\right)$

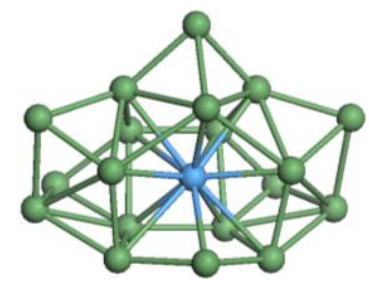

$\mathrm{TaGe}_{19}$-e $\left(\mathrm{C}_{\mathrm{s}}\right)$

Figure 2. Lowest-energy structures and their corresponding isomers of $\mathrm{TaGe}_{\mathrm{n}}(\mathrm{n}=1-19)$ clusters. For each size, the lowest-energy isomer is indicated in bold. 


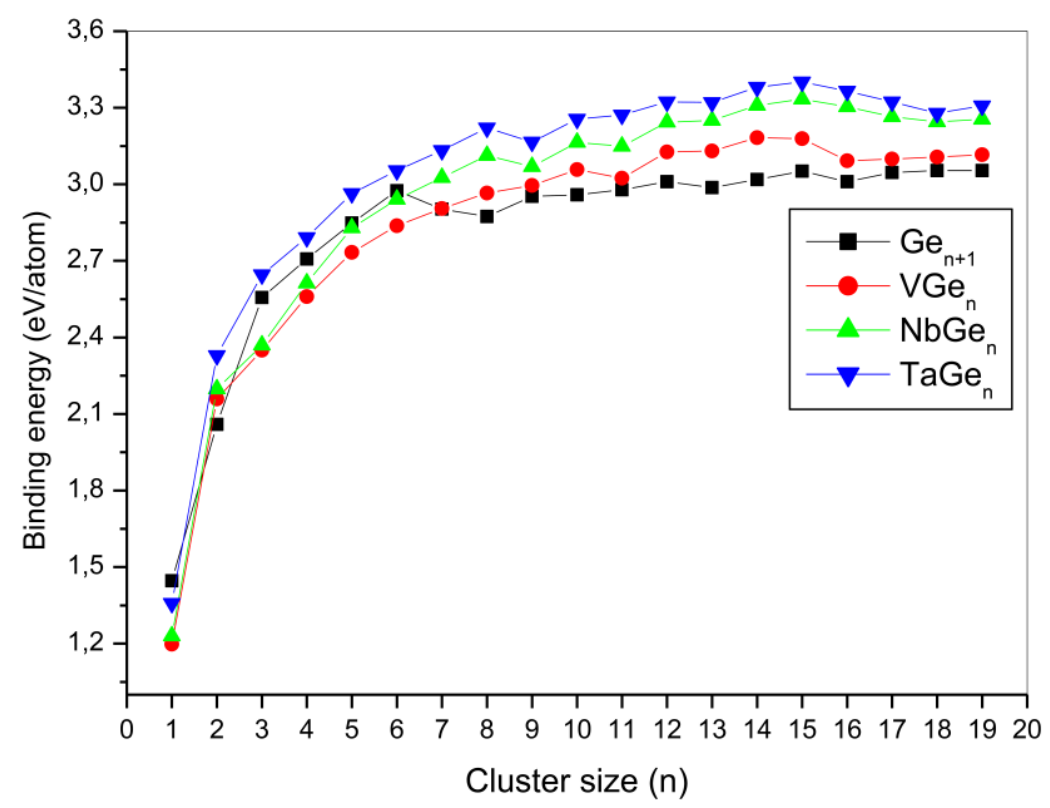

Figure 3. Binding energy (eV/atom) of the lowest-energy structures of $\mathrm{MGe}_{n}(\mathrm{M}=\mathrm{V}[31], \mathrm{Nb}$, Ta) $(n=1-19)$ clusters. 


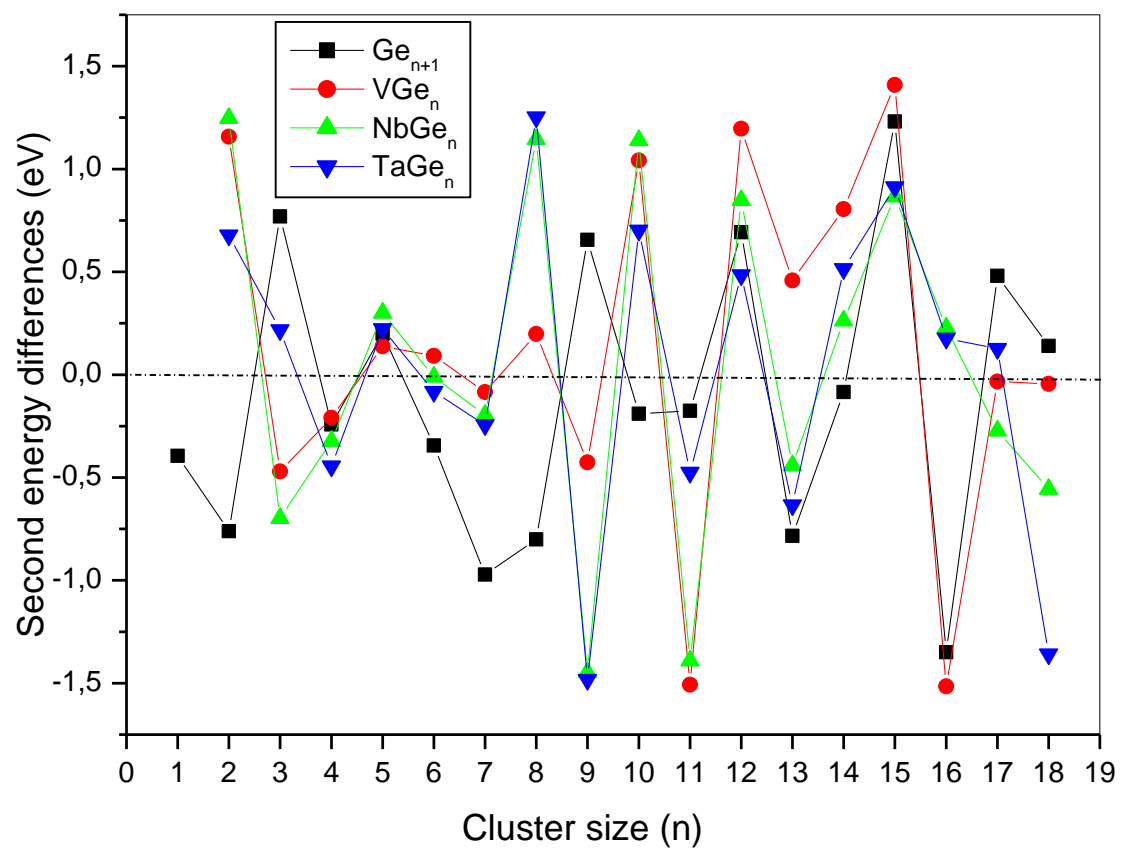

Figure 4. Second-order energy differences $\Delta_{2} \mathrm{E}(\mathrm{eV})$ of the lowest-energy structures of $\mathrm{MGe}_{\mathrm{n}}$ $(\mathrm{M}=\mathrm{V}$ [31], Nb, Ta) $(\mathrm{n}=1-19)$ clusters. 


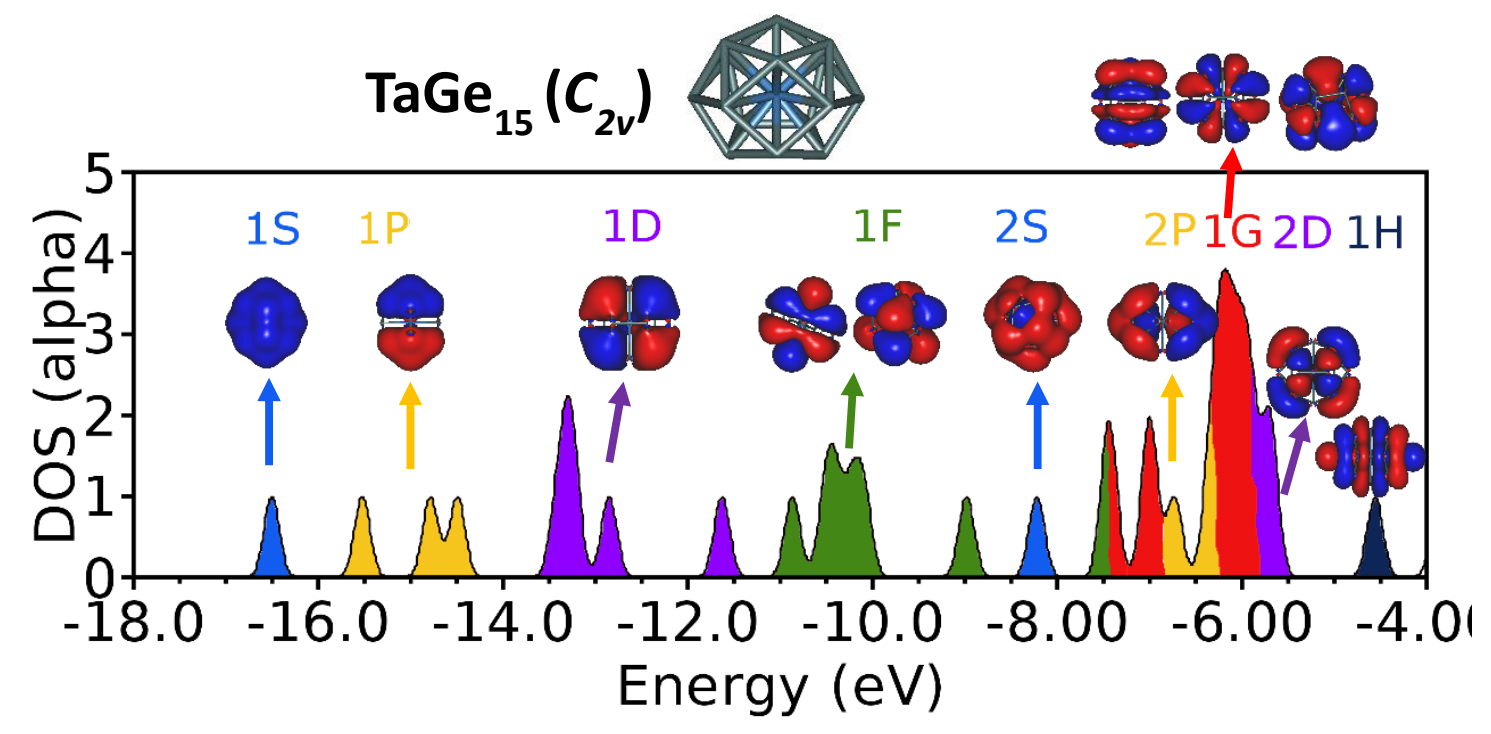

Figure 5. Density of states (DOS) of $\mathrm{TaGe}_{15}$ for alpha spin electrons. For beta spin electrons, the $1 \mathrm{H}$ orbital is empty (doublet state). For each band, the Kohn-Sham orbitals are plotted. DOS for $\mathrm{NbGe}_{15}$ is very similar. 


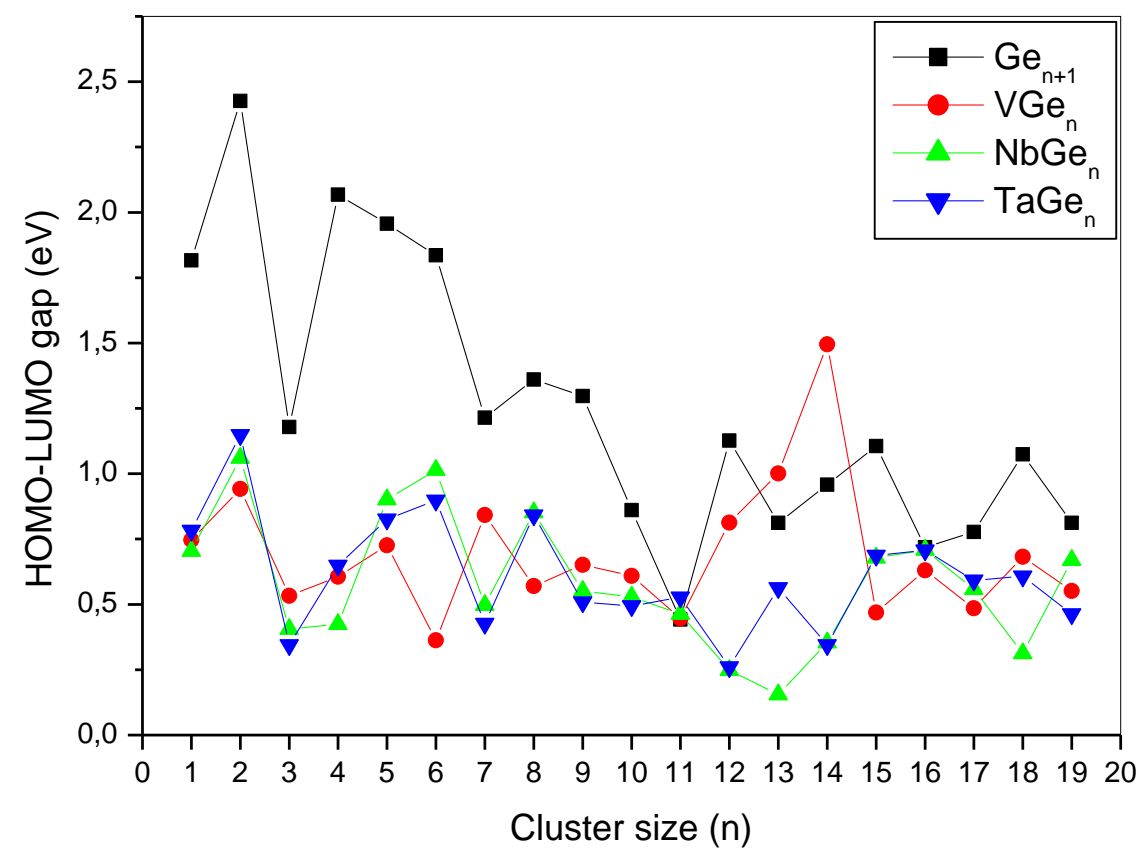

Figure 6. HOMO-LUMO gaps (eV) of the lowest-energy structures of $\mathrm{MGe}_{\mathrm{n}}(\mathrm{M}=\mathrm{V}$ [31], $\mathrm{Nb}$, Ta) $(n=1-19)$ clusters. 


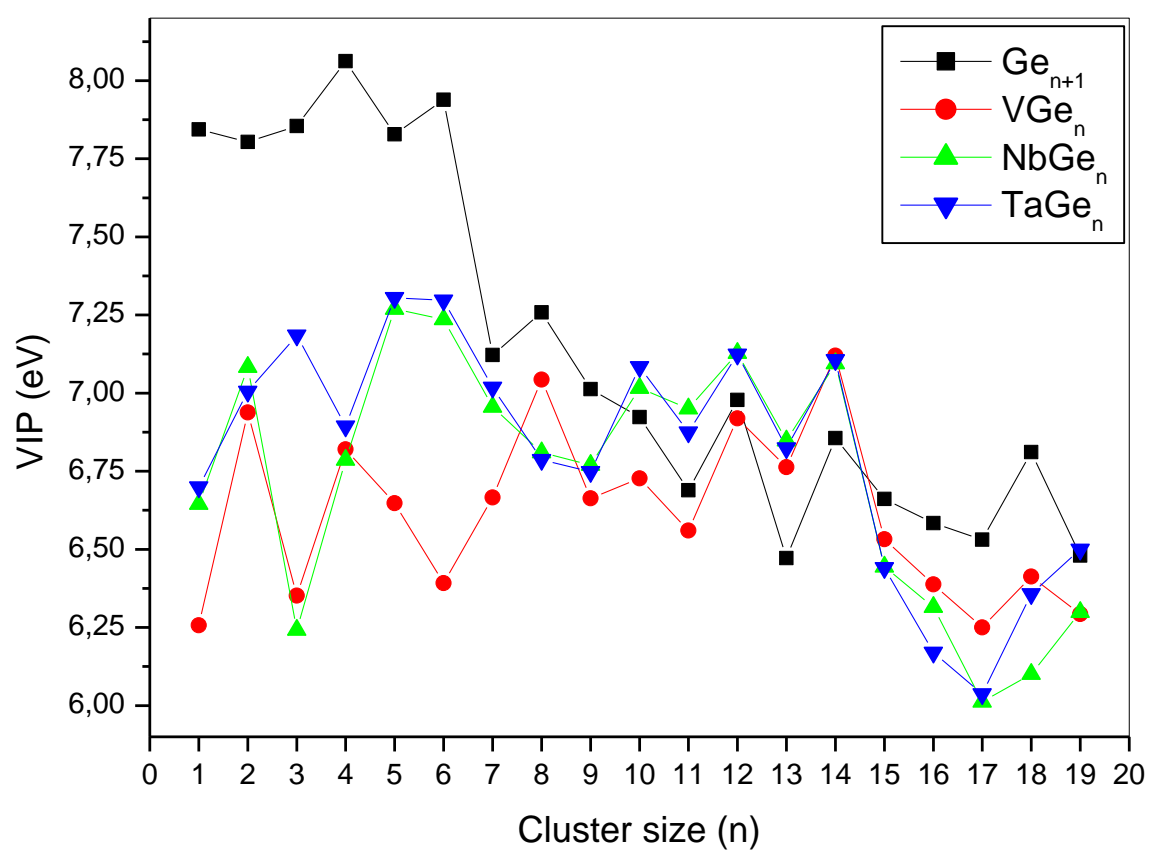

Figure 7. Vertical ionization potential VIP $(\mathrm{eV})$ of the lowest-energy structures of $\mathrm{MGe}_{\mathrm{n}}(\mathrm{M}=$ $\mathrm{V}$ [31], Nb, Ta) ( $\mathrm{n}=1-19)$ clusters. 


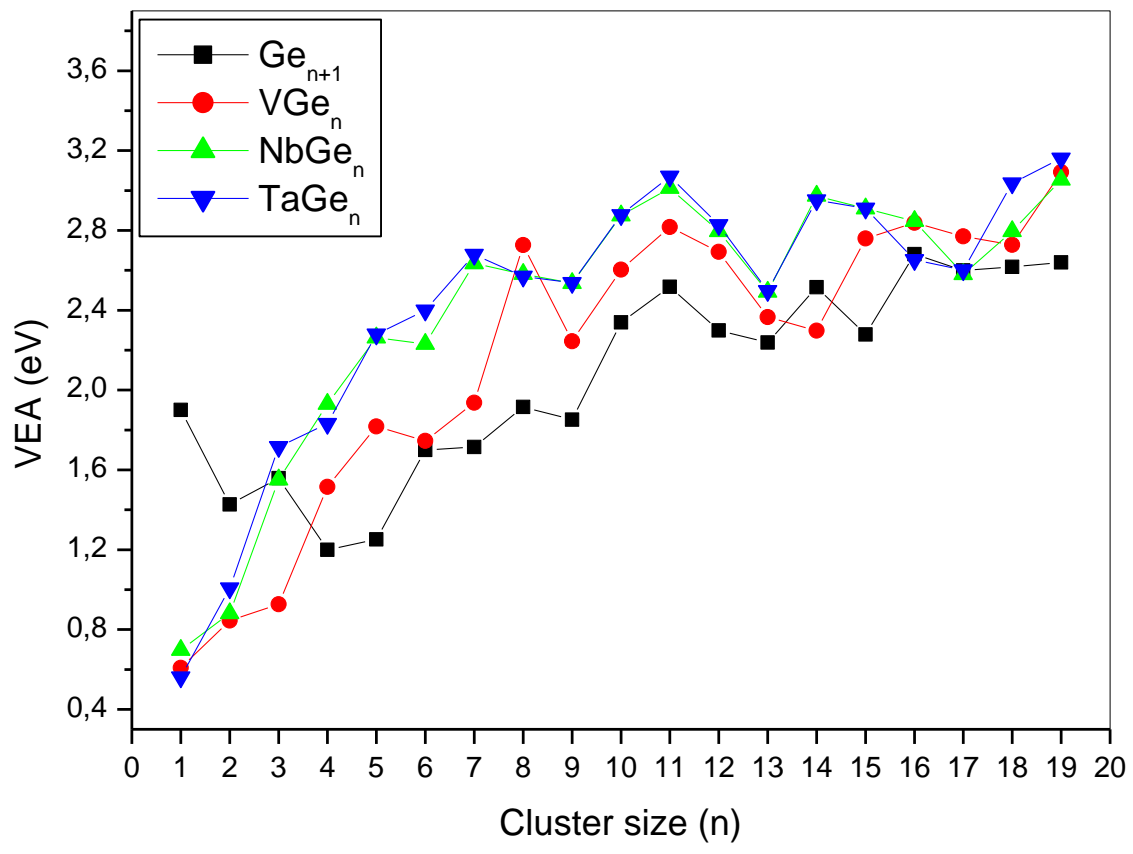

Figure 8. Vertical electron affinity VEA (eV) of the lowest-energy structures of $\mathrm{MGe}_{\mathrm{n}}(\mathrm{M}=\mathrm{V}$ [31], $\mathrm{Nb}, \mathrm{Ta})(\mathrm{n}=1-19)$ clusters. 


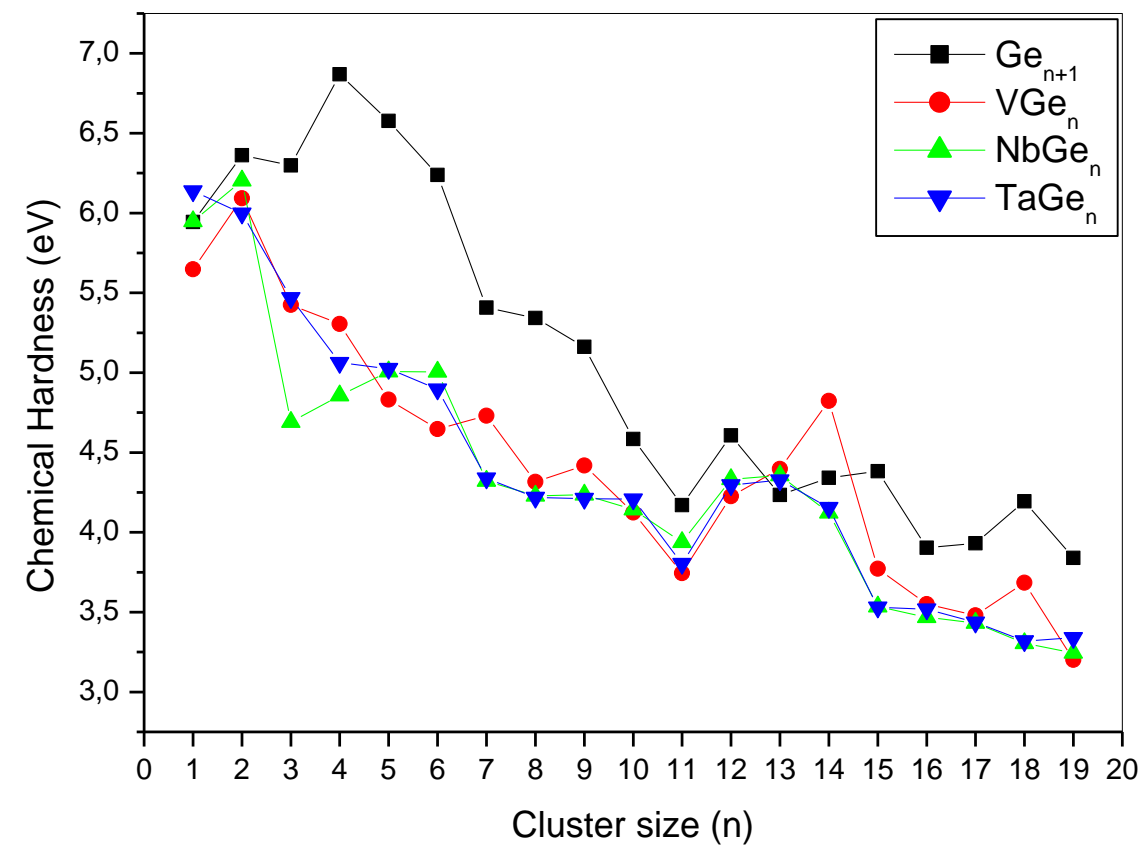

Figure 9. Chemical hardness $(\mathrm{eV})$ of the lowest-energy structures of $\mathrm{MGe}_{\mathrm{n}}(\mathrm{M}=\mathrm{V}$ [31], $\mathrm{Nb}$, Ta) $(n=1-19)$ clusters. 

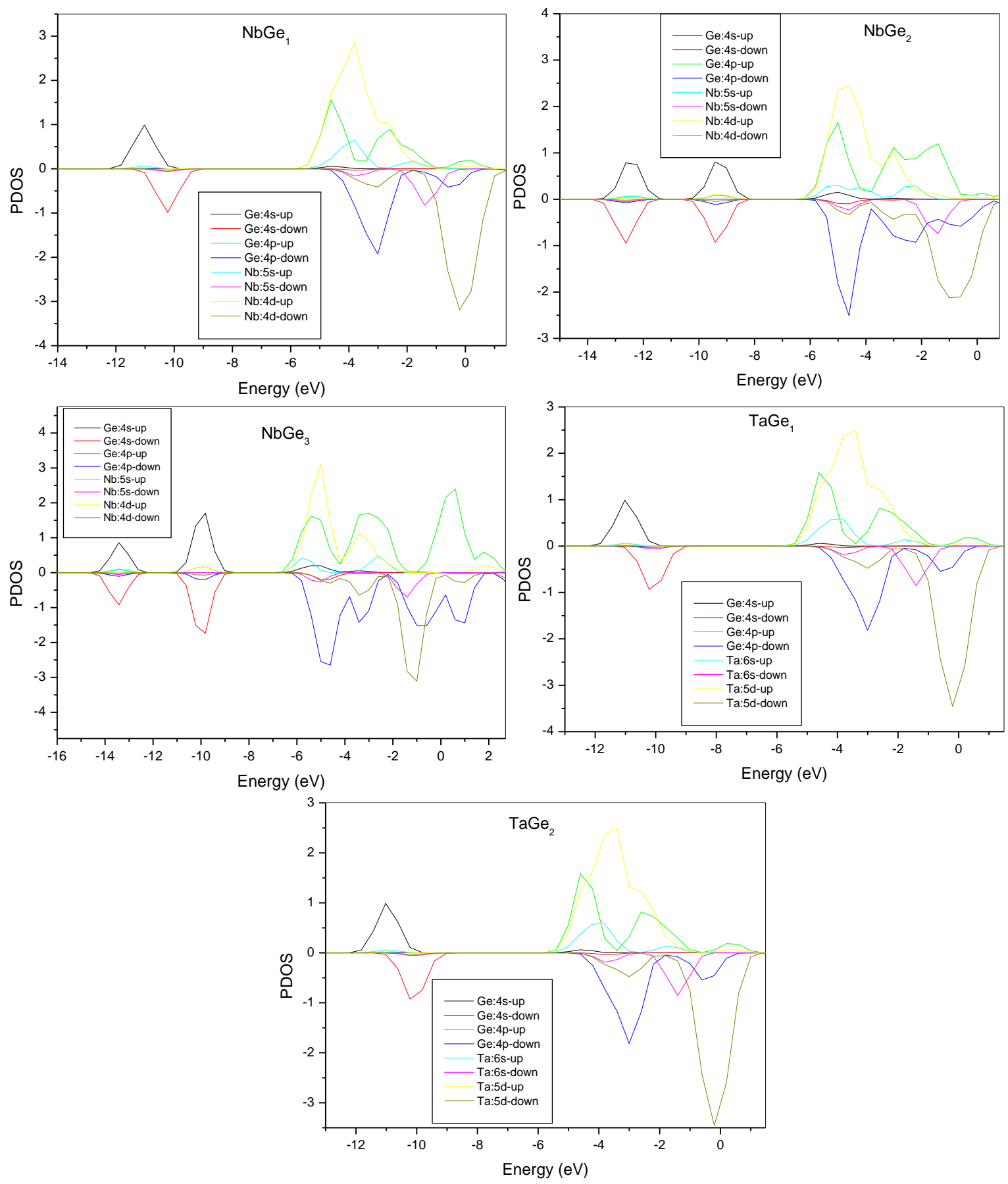

Figure 10. Projected densities of states of $\mathrm{NbGe}_{1,2,3}$ and $\mathrm{TaGe}_{1,2}$ clusters. The Fermi level has been taken as the origin of the energy. 